\title{
Relación entre los diversos usos de las redes sociales Twitter y Facebook, emociones y voto en España
}

\section{Relationship between various uses of social networks, Twitter and Facebook, emotions and voting in Spain}

\author{
José Manuel Rivera Otero. . Universidad de Santiago de Compostela. España. \\ josemanuel.rivera@usc.es \\ $[\underline{\mathrm{CV}}]$ \\ Nieves Lagares Diez. . Universidad de Santiago de Compostela. España \\ mnieves.lagares@usc.es \\ [CV] (B) \\ María Pereira López ${ }^{1}$. . Universidad de Santiago de Compostela. España \\ maria.pereira.lopez@usc.es \\ [CV] \\ Erika Jaráiz Gulías. . Universidad de Santiago de Compostela. España. \\ erika.jaraiz@usc.es \\ $[\mathrm{CV}]$
}

Cómo citar este artículo / Referencia normalizada

Rivera, J.M., Lagares, N., Pereira, M. y Jaráiz, E. (2021). Relación entre diversos usos de las redes sociales, emociones y voto en España. Revista Latina de Comunicación Social, 79,73-98. https://www.doi.org/10.4185/RLCS-2021-1518

\begin{abstract}
RESUMEN
Introducción: El objetivo que persigue este trabajo es analizar si los diversos usos que los ciudadanos realizan de las redes sociales (Twitter y Facebook) en España tienen relación con el voto a los partidos políticos y con las emociones que los ciudadanos sienten hacia los líderes. De ser así, podríamos asumir que la plataformización es un proceso politizado y emocionado y que esa politización y emocionalidad del proceso vincula el tipo de uso que los ciudadanos hacen de las redes. Metodología: Este trabajo se ha planteado como un estudio de caso mediante un enfoque metodológico cuantitativo que plantea tanto un análisis descriptivo e interdependiente de los datos. Resultados: el análisis del consumo de redes en función del voto muestra la existencia de un patrón diferenciado en función de aquel. Una tendencia que se replica en lo relativo al uso específico de las redes concretas. Discusión: los datos respecto a la expresión emocional de enfado y miedo concuerdan con las posturas defendidas en la literatura. Conclusiones: estos hallazgos se suman a los ya existentes respecto a la importancia de las redes como "cámaras de eco" que amplifican los debates que en ellas se producen, en una suerte de "espiral emocional".
\end{abstract}

\footnotetext{
${ }^{1}$ María Pereira López, autora de correspondencia.
} 
PALABRAS CLAVE: plataformización, redes sociales, Twitter, Facebook, información política, participación política, emociones, líderes políticos, España.

\begin{abstract}
Introduction: The objective pursued by this research is to determine if there is a diversified use of social networks (Twitter and Facebook) in Spain has relationship with the vote for political parties that citizens express, as well as with the presence emotional towards leaders. If so, we could assume that the plataformización is a politicized and excited process and that this politicization and emotionality of the process links the type of use those citizens make of the networks. Methodology: This work has been proposed as a case study using a quantitative methodological approach that proposes both a descriptive and interdependency analysis of the data. Results: the analysis of the consumption of networks according to the vote shows the existence of a differentiated pattern according to the latter. A trend that is replicated in relation to the specific use of specific networks. Discussion: the data regarding emotional expression of anger and fear agree with the positions defended in the literature. Conclusions: these findings are in addition to those already existing regarding the importance of networks as "echo chambers" that amplify the debates that occur in them, in a kind of "emotional spiral".
\end{abstract}

KEYWORDS: platformization, social media, Twitter, Facebook, political information, political participation, emotions, political leaders, Spain.

\title{
CONTENIDO
}

1. Introducción. 2. Objetivos. 3. Metodología. 4. Discusión/Resultados. 5. Conclusiones. 6. Bibliografía 7. Currículum Vitae 8. Anexos.

\section{Introducción}

El incremento en el uso de las redes sociales ha supuesto importantes cambios en la forma de intercambiar información entre los ciudadanos, pero también ha cambiado los modos de relación de los ciudadanos con la política. En este sentido, el proceso de plataformización (Helmond, 2015), consecuencia directa de la proliferación del uso de las redes, ha tenido en la política múltiples consecuencias que van desde su mismo uso, ya indispensable en las campañas políticas, pasando por la visualización de los liderazgos o la configuración de nuevas formas de comunicarse desde las organizaciones partidistas e incluso desde las instituciones públicas. Todo ello ha tenido a su vez importantes consecuencias en la forma en la que se traza la relación entre la ciudadanía y la política, generándose nuevos espacios dialógicos de comunicación y debate que representan desafíos para la reflexión en el seno de los sistemas democráticos.

Unos espacios de debate y diálogo que han sido definidos por algunos como "cámaras de eco" (Sunstein, 2001) donde, tanto por el funcionamiento de los diferentes algoritmos que se encuentran detrás del funcionamiento de cada una de ellas, como por la propia forma de interacción de los usuarios en ellas; las conversaciones se vuelven endógenas, retroalimentando opiniones preexistentes por parte de los participantes y generando un notable clima de tensionamiento y polarización (Colleoni, Rozza y Arvidsson, 2014; Del Vicario et al., 2015; Del Vicario et al., 2017). Una polarización que es consecuencia no sólo de las propias características intrínsecas de las redes, sino también del hecho de que se hayan constituido como espacios públicos de contagio emocional, en los que se analizan los sentimientos y se expresan afectos (Serrano-Puche, 2016).

Pero no todos los ciudadanos utilizan las redes sociales con idénticos fines. Y en este sentido, dos son los usos que, ligados a la política, han sido en mayor medida abordados por la literatura: el uso 
de las redes sociales para informarse o recibir información política y su uso para participar en política. Dos procesos que a su vez se interrelacionan y complementan, generando no sólo un consumo diferenciado del que se produce en los medios de comunicación offline (Bode, 2016), sino además formas concretas de participación política online; lo que lleva a diferenciar los comportamientos políticos que se producen en ambos entornos (Shahin, Saldaña y Gil de Zúñiga, 2020).

Desde esta perspectiva, resulta fundamental analizar los diversos usos que la ciudadanía española realiza de las redes sociales en general, de algunas en particular y de la relación que dichos usos guardan con el grado de credibilidad que les conceden, así como con el tipo de emociones hacia la política que expresan. En general, se trata de saber si como ya han apuntado trabajos anteriores (Wollebaek et al., 2019), la presencia en las redes con fines políticos tiende a reproducir emociones negativas hacia la política

\subsection{Información y participación política en redes sociales}

Como hemos mencionado, los ciudadanos utilizan de forma diferente las redes sociales, destacando en el ámbito de lo político el uso de éstas para recibir información política o para participar en política. Dos usos que se relacionan, puesto que el consumo de noticias políticas en redes tiene efectos directos en la participación política (Gil de Zúñiga, Molyneaux y Zheng, 2014); dado que, si bien en el espacio offline las acciones de informarse y participar en política se producen de forma separada, en el espacio online se producen una como consecuencia de la otra.

La participación en redes sociales se ha puesto en valor en lo relativo a las posibilidades que plantean para la expresión del nivel de compromiso político, engagement, de los usuarios con los partidos y los líderes políticos; generando como señalan algunos (Norris, 2001), unas oportunidades no conocidas hasta el momento. Cuestión esta última que también ha sido puesta en entredicho, si bien no es posible desarrollar en estas líneas la complejidad que este debate entraña.

Pero más allá de estas cuestiones, no sólo es importante señalar los diferentes usos de las redes, también las diferencias que atingen a dicho uso, lo cual nos permitiría hablar de una suerte de "especialización" de cada red social, algo que claramente se puede desprender no sólo del uso que de ellas realizan los ciudadanos, sino también del que realizan, en el ámbito político, los partidos y sus líderes. Así y mientras que Facebook se ha considerado una red utilizada habitualmente como instrumento de movilización y creación de comunidades (Stier et al., 2018), Twitter se ha desvelado como un medio para la difusión de noticias y contenido (Kwak et al., 2010), más proclive por tanto al debate e intercambio de opiniones; mientras que Instagram se ha focalizado en la difusión de contenido visual o fotográfico (Casero-Ripollés, 2018).

Parte de la literatura que ha abordado la reflexión sobre estos diferentes usos de las redes sociales, informarse de política y participar políticamente, se ha centrado en dilucidar que sucede con este consumo en términos de las opiniones previas que poseen los usuarios. Y en este sentido, el diseño de un espacio en el que se consume información participada proyecta la idea de construcción de una comunidad, resultado en gran medida de la producción de la denominada "cámara de eco" que provoca que los usuarios tiendan a buscar o a seguir en la red aquellas opiniones que tienden a reforzar sus posicionamientos previos (Garrett, 2009; Bail, 2016), fenómeno que McPherson, SmithLovin y Cook (2001) denominaron "homofilia", y a rehuir, en consecuencia, aquellas opiniones que puedan ser contrarias o incluso amenazantes. 
Esta tendencia termina provocando una suerte de "espiral polarizante" en el seno de las redes que se retroalimenta de forma constante y que resalta la importancia que los sentimientos, los afectos o las emociones, en definitiva, el componente emocional, tienen en el proceso de interacción que se produce en el seno de aquellas (Kramer, Guillory y Hancok, 2014; Del Vicario et al., 2017). Una polarización que en cualquier caso establece diferencias en función del tipo de red social, siendo especialmente relevante en el caso de la plataforma Twitter, tal y como señalan, entre otros, Yarchi, Baden y Kligler-Vilenchik (2020).

\subsection{Emociones y redes sociales}

El interés en el estudio de las emociones ha ido in crescendo en los últimos veinte años desde diferentes ámbitos disciplinares. Concretamente en la ciencia política su estudio, tanto desde un punto de vista teórico como empírico, ha estado muy ligado al análisis del comportamiento; lo que lo ha conectado a su vez con los estudios surgidos en el ámbito psicofisiológico. En este terreno, uno de los enfoques teóricos más prolíficos y que ha experimentado un mayor seguimiento en trabajos posteriores es la Teoría de la Inteligencia Afectiva (Marcus et al., 2000), a partir de la cual los autores sientan las bases de toda una construcción respecto a la evaluación emocional que los individuos llevamos a cabo en nuestra vida diaria a la hora de tomar decisiones y, en consecuencia, también en el ámbito de la política.

Pero esta visión de carácter cognitivo no es, ni mucho menos, la única visión que del análisis de las emociones nos podemos encontrar. En sectores más próximos a la sociología y la ciencia política, se han desarrollado otros enfoques que desde una visión culturalista han abogado por la defensa de las emociones como una construcción social (Harré, 1986; Elster, 2002), las emociones se construirían socialmente a través de diferentes mecanismos de activación, siendo necesario conocer en profundidad las sociedades en las que se producen. Ambas visiones, cognitiva y constructivista, no son en absoluto excluyentes, entendemos, sino más bien complementarias, y especialmente útiles para comprender el estudio de las emociones en el ámbito de la comunicación y más concretamente, en el terreno de las redes sociales. Y esta afirmación se sustenta en dos hechos fundamentales, que las redes son espacios idóneos para el debate emocionado y para la construcción de comunidades.

Uno de los aspectos en los que se ha puesto el acento en el estudio de las emociones ligadas a la comunicación, es en cómo se consume y procesa la información recibida (Neuman et al., 2018); puesto que se ha demostrado que el consumo de información política en las redes provoca fuertes respuestas emocionales. Esto ha llevado a que los estudios hayan profundizado en el tipo de emociones concretas que se producen en relación con el consumo de información política, es el caso del análisis del miedo y el enfado como emociones negativas (Vasilopoulos, Marcus y Foucault, 2018, Vasilopoulos et al., 2018) o el entusiasmo (Marcus, 2019; Marcus et al., 2019) como emoción positiva.

Centrándonos en las emociones negativas, concretamente en el miedo y el enfado, algunos trabajos han resaltado el impacto diverso que ambas tendrían sobre la forma en que se comportan los usuarios de redes sociales. Pues, como señalan Wollebaek et al. (2019) mientras que el enfado llevaría a las personas a la búsqueda de información o a la participación en debates con otras personas que compartan sus mismos o similares puntos de vista; el miedo, en cambio, llevaría a las personas a buscar información diversa, en un intento por hacerse con diferentes puntos de vista. Y estas dos dinámicas tan diferentes, no son más que el resultado de dos procesos distintos de activación emocional: el primero impulsado por un comportamiento de riesgo, y el segundo, por un comportamiento de aversión a aquel (Lerner y Keltner, 2001; Vasilopoulos, Marcus y Foucault, 2018, Vasilopoulos et al., 2018). 
Si bien dentro de las emociones positivas el orgullo y el entusiasmo han sido dos de las emociones más trabajadas, siendo perfiladas como activadores emocionales de la acción y la construcción política (Marcus et al., 2000; 2017); no ha sido así en el caso de la esperanza, y mucho menos en cuanto a la tranquilidad. En el caso de la primera, desde que Weber aludiera a su importancia para la acción de una comunidad política, algunos trabajos han profundizado en su análisis desde el ámbito de la neurociencia (Botvinick y Braver, 2015;) y la psicología social. Estos trabajos dibujan la esperanza como una herramienta de compromiso y lealtad con una acción u objeto, incluso cuando las amenazas o las expectativas pueden desviar la atención de los individuos. La esperanza se perfila así, como sustentadora en el tiempo de las acciones individuales o colectivas en la sociedad (Averill et al., 1991: 284), pero también como alentadora de la acción (Lazarus, 1999). Particularmente, trabajos como el de Jones, Hoffman y Young (2013) muestran como la percepción de esperanza en un candidato aumenta la probabilidad de participación política entre los individuos con altos niveles de consumo de medios.

En cuanto al estudio de la tranquilidad, éste ha sido mucho más reducido e incluso prácticamente inexistente dentro de la ciencia política y la psicología, en parte porque se ha generado cierto debate sobre si estamos ante una emoción o una actitud. Cabe señalar que sí se ha empleado este término para describir estados emocionales de baja excitación y valencia positiva como la satisfacción y la serenidad (Fredrickson, 1998: 306) o el sentirse contento; teniendo así un carácter transversal para designar un estado emocional placentero (Cordaro et al, 2016). Desde la Teoría de la Inteligencia Afectiva, la tranquilidad o calma ha sido asumida como un estado emocional contrario a la ansiedad (Marcus et al., 2000: 56).

Nuestra investigación intenta aunar estas visiones, partiendo de la idea de que las redes sociales son espacios de consumo de información, proclives al intercambio de mensajes con fuerte carga emocional, los cuales tienen además mayor probabilidad de ser compartidos entre las diferentes comunidades digitales (Brady et al., 2017; Knoll, Matthes and Heiss, 2020). Por esta razón, y en la línea de trabajos anteriores basados también en estudios demoscópicos (Kramer, Guillory y Hancock, 2014; Hasell y Weeks, 2016; Wollebaek et al., 2019;), entendemos fundamental profundizar en los usos que los ciudadanos realizan de las redes, con especial atención al tipo de emociones que en ellas se producen y al papel que éstas juegan en la construcción del comportamiento político online.

\section{Objetivos}

El objetivo central que persigue esta investigación es determinar si existe en España un uso diversificado de las redes sociales, concretamente de Twitter y Facebook, y cuál es la relación que dicho uso guarda con el voto a los partidos políticos (politización) que manifiestan los ciudadanos, así como con la presencia emocional hacia los principales líderes políticos.

A su vez este objetivo nos llevaría a plantear tres hipótesis de investigación de partida:

- H1: el uso con fines políticos de las redes sociales bien sea para recibir información política o para participar políticamente, está mediatizado por el posicionamiento político de los ciudadanos.

- H2: existe una relación entre el tipo de redes sociales que usan los ciudadanos y el posicionamiento político de éstos.

- H3: cuanto más proactivo sea el uso político que se realiza de las redes sociales mayor es la expresión emocional que hacia los líderes políticos sienten los ciudadanos. 


\section{Metodología}

Este trabajo se ha planteado como un estudio de caso y se ha trazado mediante un enfoque metodológico cuantitativo que plantea tanto un análisis descriptivo como interdependiente de los datos aportados.

El análisis se ha construido a través de la explotación e interpretación de los resultados extraídos de la base de datos creada por el Anonimizado, titulado Estudio Política y Emociones en España. Febrero, 2021 (EPEE, Fef. 2021). Se trata de un completo estudio de carácter político en el que se incluyen temas fundamentales de interés científico tales como: consumo de medios de comunicación offline y online, análisis de las emociones expresadas hacia los líderes y los partidos políticos españoles, cleavages políticos, análisis del liderazgo político, monarquía y democracia, confianza en la clase política y en las instituciones, ... entre otros muchos. A continuación, en la tabla 1, se aportan los detalles técnicos del mismo.

Tabla 1. Información técnica de la base de datos utilizada en el análisis

\begin{tabular}{|c|c|c|}
\hline Año & Nombre estudio & Datos técnicos \\
\hline 2021 & $\begin{array}{l}\text { Estudio Política y Emociones } \\
\text { en España. Febrero } 2021 \\
(\text { EPEE, Feb. 2021) }\end{array}$ & $\begin{array}{l}\text { Fechas: Del } 18 \text { de enero al } 18 \text { de febrero de } 2021 . \\
\text { Universo: población mayor de } 18 \text { años, residente en España. } \\
\text { Tamaño muestral: } 1000 \text {. } \\
\text { Supuestos: } \mathrm{p}=\mathrm{q} . \\
\text { Error asociado: } \pm 3,17 \% \text {. } \\
\text { Afijación: proporcional (cuotas de sexo y edad). } \\
\text { Administración: telefónicamente mediante el sistema CATI. }\end{array}$ \\
\hline
\end{tabular}

Fuente: elaboración propia.

Como ya se ha mencionado, para esta investigación hemos trabajado únicamente con algunas de las variables de este amplio estudio. Las variables centrales de nuestro análisis son aquellas relativas a los diferentes usos que de las redes realiza la población española; así como variables relativas al posicionamiento político de los electores, a través de la variable, recuerdo de voto en las últimas elecciones generales celebradas en noviembre de 2019; y la medición del componente emocional hacia la política, expresado a través de la presencia emocional hacia los principales líderes políticos que afirman sentir los ciudadanos. Los detalles técnicos respecto a la forma de medición de cada una de estas variables se recogen en la tabla 2.

Nos gustaría dedicar unas líneas de este apartado a exponer brevemente la importancia y sentido que el análisis de las emociones tiene no sólo en este estudio demoscópico, sino en el conjunto de los trabajos que el EIP-USC ha desarrollado. Así pues, la materialización empírica de este componente se sustenta en una batería compuesta por trece emociones sobre las cuales se miden tres cuestiones fundamentales: la presencia, la intensidad y la duración de la expresión emocional hacia líderes y partidos políticos. Doce de las trece emociones analizadas se corresponden con la solución ortogonal full set planteada en la Pilot Study ANES 1995 (Marcus et al., 2000): orgullo, esperanza, entusiasmo, ansiedad, miedo, preocupación, enfado, resentimiento, disgusto, odio, desprecio y amargura; a la que se ha añadido una más, tranquilidad ${ }^{2}$. Siguiendo a los autores, las emociones pueden ser agrupadas en tres componentes emocionales: a) Entusiasmo (positivas): tranquilidad, orgullo, esperanza y

\footnotetext{
${ }^{2}$ Tal y como explican los autores, desde el año 1980, el estudio realizado por la ANES incluía únicamente cuatro emociones (dos positivas y dos negativas), en el año 1985 se amplió la batería a un total de doce, añadiendo un nuevo ítem positivo y siete negativos.
} 
entusiasmo; b) Ansiedad (negativas): miedo, disgusto, preocupación, enfado y ansiedad; y c) Aversión (muy negativas): resentimiento, amargura, desprecio y odio ${ }^{3}$.

Tabla 2. Variables utilizadas en el análisis

\begin{tabular}{|c|c|c|}
\hline Variable & Forma de medición & Tipo de variable \\
\hline $\begin{array}{l}\text { Usuario habitual de redes } \\
\text { sociales }\end{array}$ & ¿Es Ud. usuario habitual de las redes sociales? & $\begin{array}{l}\text { Nominal dicotómica, } \\
\text { respuesta simple cerrada }\end{array}$ \\
\hline $\begin{array}{lcr}\text { Redes } & \text { sociales } & \text { que } \\
\text { consume } & \text { con } & \text { más } \\
\text { frecuencia } & \text { para consultar } \\
\text { información política }\end{array}$ & ¿De qué red social es usted usuario habitual? & $\begin{array}{l}\text { Nominal politómica, } \\
\text { respuesta múltiple cerrada } \\
\text { Filtrada (sólo si afirma ser } \\
\text { usuario habitual de redes) }\end{array}$ \\
\hline $\begin{array}{l}\text { Frecuencia de uso de las } \\
\text { redes sociales }\end{array}$ & $\begin{array}{l}\text { Y, por favor, ¿podría decirme con qué frecuencia las } \\
\text { utiliza? }\end{array}$ & $\begin{array}{l}\text { Nominal politómica, } \\
\text { respuesta simple cerrada }\end{array}$ \\
\hline $\begin{array}{l}\text { Uso de redes sociales para } \\
\text { informarse de política }\end{array}$ & $\begin{array}{l}\text { ¿Usa Ud. las redes sociales para recibir información } \\
\text { política? }\end{array}$ & $\begin{array}{l}\text { Nominal dicotómica, } \\
\text { respuesta simple cerrada } \\
\text { Filtrada (sólo si afirma ser } \\
\text { usuario habitual de redes) }\end{array}$ \\
\hline $\begin{array}{l}\text { Frecuencia uso de redes } \\
\text { sociales para recibir } \\
\text { información política }\end{array}$ & $\begin{array}{l}\text { En una escala de } 0 \text { a } 10 \text {, donde } 0 \text { es nada y } 10 \text { mucho, } \\
\text { ¿cuál es el uso que Ud. hace de las redes para recibir } \\
\text { información política? }\end{array}$ & $\begin{array}{l}\text { Escalar (0-10) } \\
\text { Filtrada (sólo si afirma usar } \\
\text { las redes sociales para } \\
\text { informarse de política) }\end{array}$ \\
\hline $\begin{array}{l}\text { Uso de redes sociales para } \\
\text { informarse de política }\end{array}$ & ¿Usa Ud. las redes sociales para participar en política? & $\begin{array}{l}\text { Nominal dicotómica, } \\
\text { respuesta simple cerrada } \\
\text { Filtrada (sólo si afirma ser } \\
\text { usuario habitual de redes) }\end{array}$ \\
\hline $\begin{array}{l}\text { Frecuencia uso de redes } \\
\text { sociales para participar en } \\
\text { política }\end{array}$ & $\begin{array}{l}\text { En una escala de } 0 \text { a } 10 \text {, donde } 0 \text { es nada y } 10 \text { mucho, } \\
\text { ¿cuál es el uso que Ud. hace de las redes para participar } \\
\text { en política? }\end{array}$ & $\begin{array}{l}\text { Escalar }(0-10) \\
\text { Filtrada (sólo si afirma usar } \\
\text { las redes sociales para } \\
\text { participar en política) }\end{array}$ \\
\hline $\begin{array}{l}\text { Nivel de credibilidad } \\
\text { medios de comunicación }\end{array}$ & $\begin{array}{l}\text { ¿En qué medida usted le da credibilidad a la } \\
\text { información recibida a través de los siguientes medios } \\
\text { de comunicación? En una escala de } 0 \text { a } 10 \text {, donde } 0 \\
\text { significa mucha y } 10 \text { poca. }\end{array}$ & Escalar (0-10) \\
\hline $\begin{array}{l}\text { Razones del nivel de } \\
\text { credibilidad en los medios } \\
\text { de comunicación }\end{array}$ & $\begin{array}{l}\text { ¿Cuáles son las principales razones que motivarían } \\
\text { dicha credibilidad? }\end{array}$ & $\begin{array}{l}\text { Nominal politómica, } \\
\text { respuesta múltiple cerrada }\end{array}$ \\
\hline Recuerdo de voto & $\begin{array}{l}\text { Como Ud. sabe el } 10 \text { de noviembre de } 2019 \text { se } \\
\text { celebraron Elecciones Generales. ¿Podría decirme a qué } \\
\text { partido votó Ud.? }\end{array}$ & $\begin{array}{l}\text { Nominal politómica, } \\
\text { respuesta simple } \\
\text { semicerrada }\end{array}$ \\
\hline $\begin{array}{l}\text { Presencia emocional hacia } \\
\text { los principales líderes } \\
\text { políticos (Pedro Sánchez, } \\
\text { Pablo Casado, Pablo } \\
\text { Iglesias, Inés Arrimadas y } \\
\text { Santiago Abascal) }\end{array}$ & $\begin{array}{l}\text { Piense ahora en sus emociones, en las emociones que } \\
\text { nos hacen sentir los políticos, aunque a veces no seamos } \\
\text { muy conscientes. Le voy a citar una serie de políticos y } \\
\text { le ruego que me diga si alguna vez le han hecho sentir } \\
\text { alguna de las emociones de las que le voy a hablar }\end{array}$ & Nominal dicotómica cerrada \\
\hline
\end{tabular}

Fuente: elaboración propia.

\section{Discusión/Resultados}

\footnotetext{
${ }^{3}$ Para más información sobre estas cuestiones consultar, Anonimizado.
} 


\subsection{Análisis preliminar: usos de las redes sociales, recuerdo de voto y emociones}

Comenzamos el análisis preliminar presentando en términos generales los valores de uso de las redes sociales en España en la actualidad. Como se puede observar en el esquema 1 el 51,7\% de los españoles se declaran usuarios habituales de redes sociales, hecho que se confirma cuando se les pregunta por su frecuencia de uso, puesto que el 73,6\% de los que afirman utilizarlas habitualmente, lo hace todos o casi todos los días (ver tabla 5 Anexos). Las principales redes sociales utilizadas son por orden de uso: Facebook (62,5\%), Instagram $(45,8 \%)$ y Twitter $(30,3 \%)$. Pero este porcentaje de uso se reduce notablemente cuando centramos el uso de las redes sociales en el ámbito de lo político (esquema 1): el 31,8\% de los ciudadanos que usan las redes habitualmente, afirman hacerlo para recibir información política, con una frecuencia media de uso del 5,8 sobre 10; y el 14,2\% afirma hacerlo para participar en política, con una frecuencia media de uso del 5,12 sobre 10. Nos gustaría advertir, que estos porcentajes son ligeramente inferiores a los que hemos podido observar en anteriores estudios realizados tras la celebración de las elecciones generales de abril y noviembre de $2019^{4}$. Entendemos que estas diferencias guardan relación directa con el impacto que las campañas electorales tendrían en el incremento de estos usos. En el caso del estudio que manejamos en esta ocasión, al no tratarse de un estudio postelectoral, presenta unos porcentajes de uso inferiores, consecuencia, probablemente, de ser un período de inactividad electoral.

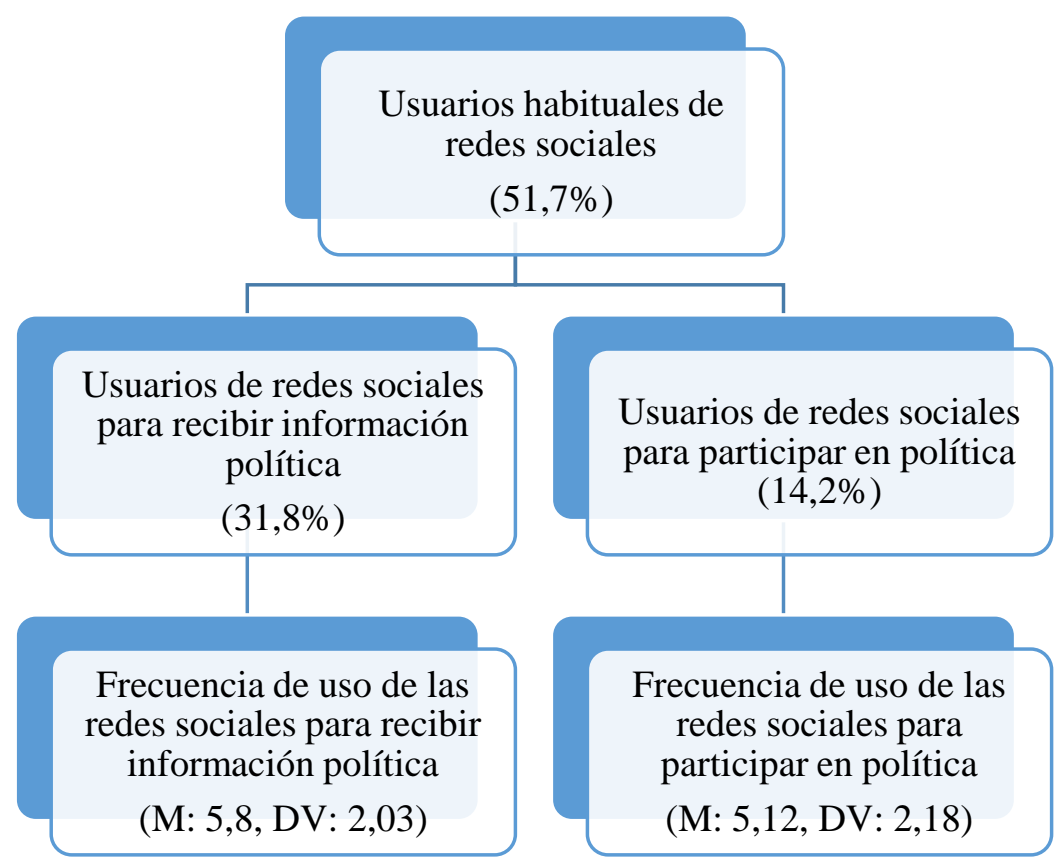

Esquema 1. Usos de redes sociales en España, 2021

Fuente: elaboración propia a partir de la base de datos EPEE, Feb. 2021 del EIP-USC.

\footnotetext{
${ }^{4}$ Los valores de uso habitual de redes sociales fueron del 51,2\% en A2019 y del 52\% en N2019. En el caso del uso para recibir información política los valores fueron: $50 \%$ en A2019 (frecuencia media de uso 6,37) y $46,7 \%$ en N2019 (frecuencia media de uso 6,8). Los valores de uso de redes para participar en política fueron: $21,9 \%$ en A2019 (frecuencia media de uso 6,13) y 21,4\% en N2019 (frecuencia media de uso 6,22).
} 
- No usuarios habituales de redes sociales

- Usuario de redes sociales para recibir información política
- Usuario habitual de redes sociales

- Usuario de redes sociales para participar en política

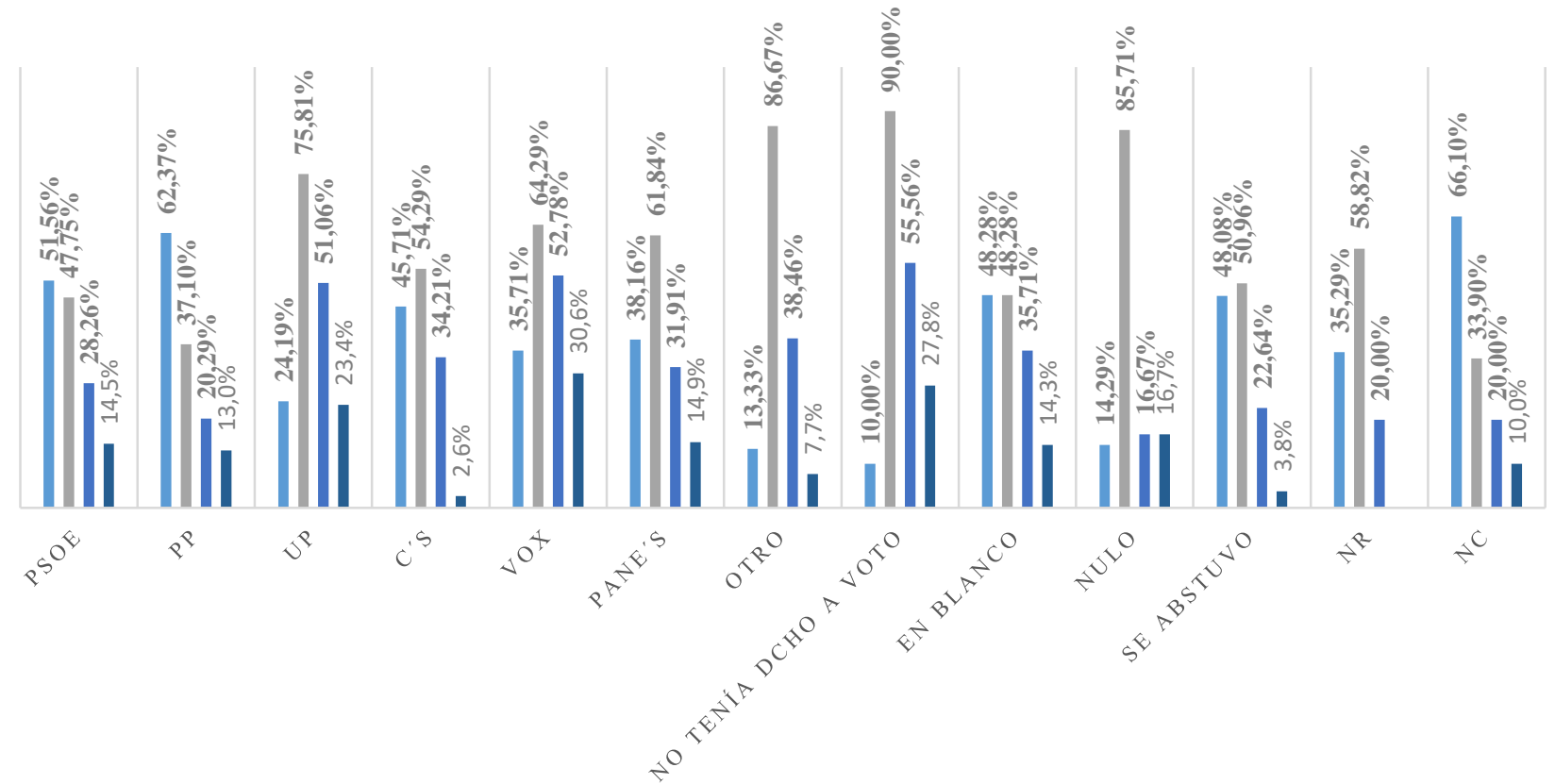

Gráfico 1. Usos de las redes sociales según recuerdo de voto en las elecciones generales de noviembre de 2019 en España

Fuente: elaboración propia a partir de la base de datos EPEE, Feb. 2021 del EIP-USC.

Pero ¿qué sucede cuando observamos la relación que el uso de las redes sociales guarda con el posicionamiento político de los electores? Pues, que tal y como se puede observar en el siguiente gráfico, existen patrones diferenciados. Así, el análisis de contingencia realizado del consumo de redes en función del recuerdo de voto en las últimas elecciones generales celebradas en España en noviembre de 2019 (gráfico 1); muestra la existencia de un patrón diferenciado de consumo en función del voto, tanto para el consumo general de redes, como para su uso con fines políticos (para recibir información política o para participar en política) y en consecuencia, con los posicionamientos ideológicos de los partidos y de sus votantes ${ }^{5}$.

Unas tendencias, las definidas en lo relativo a los distintos usos de las redes sociales según el recuerdo de voto, que de nuevo encontramos cuando hablamos de las redes concretas que utilizan con mayor frecuencia los ciudadanos. Así, y tal y como se puede observar en el gráfico 2, mientras que el consumo de redes por parte de los votantes de los partidos centrípetos (PSOE, PP y C's) es más homogéneo, formando un bloque que realiza un notable uso de Facebook como principal red social, seguida de Instagram pero con casi 20 puntos porcentuales de diferencia; los partidos centrífugos, aquellos situados en los extremos ideológicos (VOX y UP), muestran patrones de consumo similares, marcados por un uso más compensado de las principales redes sociales, y en especial de Twitter, una red mucho más politizada y polarizada. En consecuencia, podríamos afirmar que las diferencias no vienen marcadas tanto por la ideología de los partidos políticos como por el

5 El análisis realizado del consumo de medios en función de la autoubicación ideológica de los entrevistados en la escala izquierda-derecha arrojó resultados similares, reafirmando lo recogido en estos gráficos y en esta afirmación. Por cuestiones de espacio ha sido imposible reproducir el análisis en estas páginas. 
posicionamiento concreto en dicha escala de cada uno de ellos. Estos datos están en consonancia con lo observado para España en trabajos anteriores en el caso de VOX (Oñate y López-López, 2020).

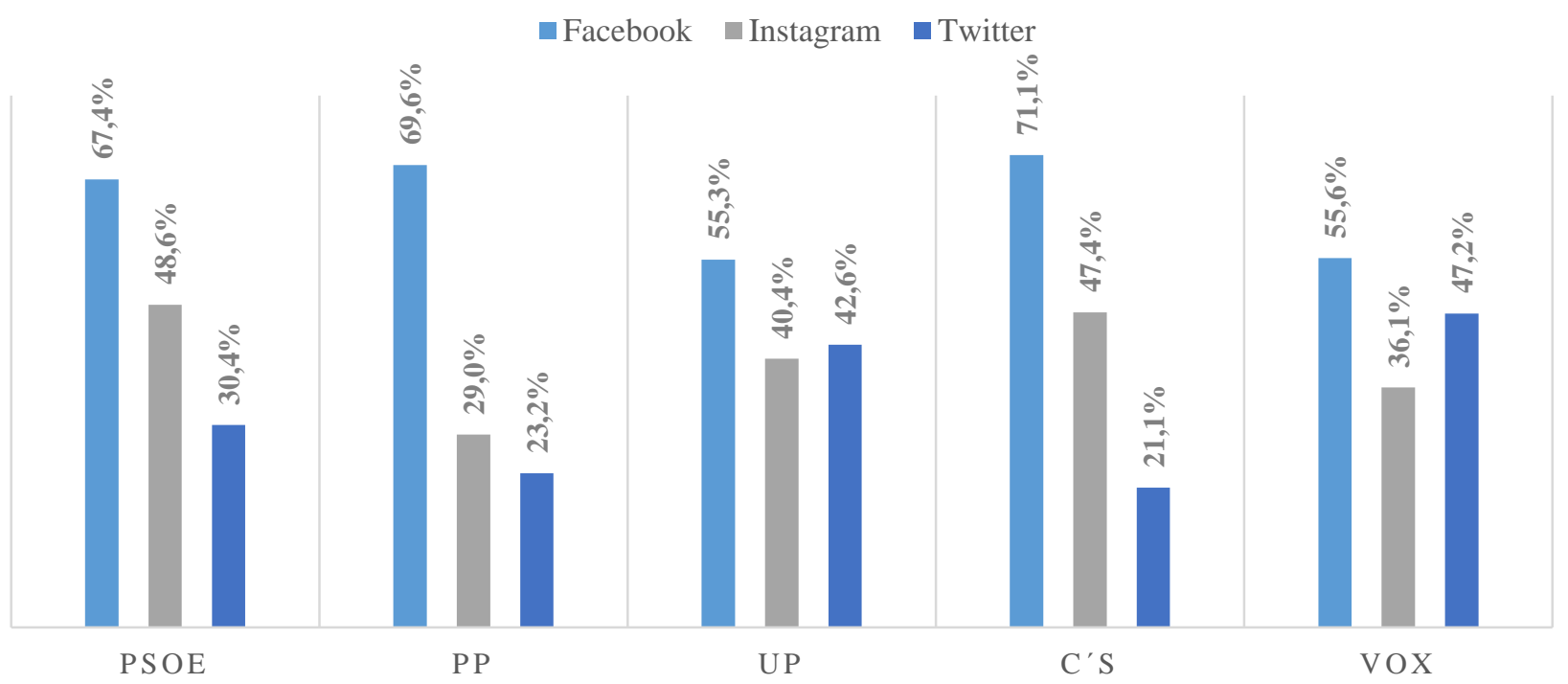

Gráfico 2. Principales redes sociales utilizadas según recuerdo de voto en las elecciones generales de noviembre de 2019 en España

Fuente: elaboración propia a partir de la base de datos EPEE, Feb. 2021 del EIP-USC.

Otra de las cuestiones que apuntábamos en el segundo apartado de este trabajo que sería también objeto de análisis es el nivel de credibilidad que los usuarios otorgan a las redes sociales en comparación a otros medios de comunicación offline. El motivo de esta reflexión radica en una de las preguntas a las que nos condujeron anteriores hallazgos: ¿es el uso de las redes resultado de otorgarles un mayor nivel de credibilidad como medio de comunicación o, por el contrario, su uso está más bien motivado por un carácter instrumental, como medio de comunicación en el cuál, como ya adelantábamos, las opiniones se refuerzan e incluso polarizan?

Para intentar dar respuesta a estas cuestiones, llevamos a cabo un análisis del nivel de credibilidad que los ciudadanos otorgan a las redes según el uso que hacen de las mismas y el posicionamiento político que manifiestan en torno a las principales formaciones. Como se desprende de la tabla 3, independientemente del tipo de uso que el ciudadano realice de las redes sociales, éstas son el medio de comunicación que genera menores niveles de credibilidad, siendo la radio, seguida de la prensa escrita, los que obtienen mayores niveles medios. A pesar de ello, sí es cierto que podemos encontrar algunas diferencias, siendo aquellos que afirman usar las redes para informarse de política quienes les otorgan un mayor nivel de credibilidad, seguidos de quienes afirman usarlas para participar en política y de quienes se definen como usuarios habituales en general. Los que menores niveles de credibilidad otorgan a las redes, con un valor medio notablemente bajo (2,32 sobre 10) son los ciudadanos que no se declaran usuarios de redes sociales, tal y como cabría esperar; lo que los llevaría al consumo de otros medios de comunicación como espacios desde los que obtener información fiable y creíble. 
RLCS, Revista Latina de Comunicación Social, 79, 73-98

[Investigación] DOI: 10.4185/RLCS-2021-1518| ISSN 1138-5820| Año 2021

Tabla 3. Nivel de credibilidad otorgado a los medios de comunicación offline y online según usos de las redes sociales en España

\begin{tabular}{|l|c|c|c|c|}
\hline & $\begin{array}{c}\text { No Usuarios } \\
\text { de redes } \\
\text { sociales }\end{array}$ & $\begin{array}{c}\text { Usuarios } \\
\text { habituales } \\
\text { redes sociales }\end{array}$ & $\begin{array}{c}\text { Usuarios de } \\
\text { redes sociales } \\
\text { para recibir } \\
\text { información } \\
\text { política }\end{array}$ & $\begin{array}{c}\text { Usuarios de } \\
\text { redes sociales } \\
\text { para participar } \\
\text { en política }\end{array}$ \\
\hline Prensa digital & 5,37 & 5,52 & 5,81 & 5,63 \\
\hline Prensa escrita & 5,75 & 5,67 & 5,84 & 5,7 \\
\hline Radio & 5,99 & 5,95 & 6,09 & 5,94 \\
\hline Televisión & 5,25 & 5,2 & 5,23 & 4,87 \\
\hline Redes sociales & 2,32 & 3,78 & 4,69 & 4,46 \\
\hline
\end{tabular}

Fuente: elaboración propia a partir de la base de datos EPEE, Feb. 2021 del EIP-USC.

Estos valores de credibilidad vienen motivados, en los diferentes medios de comunicación, por distintas cuestiones. En el caso que nos ocupa, las redes sociales, y atendiendo a los diferentes usos que los ciudadanos realizan de las mismas, puede comprobarse (gráfico 3) que la principal razón que aduce la ciudadanía para otorgar mayor o menor grado de credibilidad a la información obtenida a través de ellas son, independientemente del uso, la existencia de influencias políticas, con valores que fluctúan entre el $60 \%$ de aquellos que se declaran usuarios habituales y el 65,4\% de quienes utilizan las redes para recibir información política. Seguida, pero con valores notablemente menores, por la presencia de fake news y la influencia de los propietarios de los medios de comunicación. En el primero de estos dos últimos casos, con valores que oscilan entre el $36 \%$ de quienes son usuarios habituales de las redes en general y el 40,9\% de quienes las utilizan para recibir información política; y en el caso del segundo, con valores que van del 23,9\% de quienes las utilizan para recibir información política y el $35,7 \%$ de quienes las utilizan para participar en política.

Para finalizar este análisis respecto de la credibilidad y atendiendo a los valores comentados en la tabla 3, cabría preguntarse si dichos niveles de credibilidad, concretamente los expresados hacia las redes sociales, presentan diferencias atendiendo al posicionamiento de voto de los electores. En este sentido y tal y como se desprende de la tabla 4, se repite por partido el patrón descrito a nivel general según los distintos tipos de usuarios. Este hecho nos lleva a observar cómo son quienes usan las redes para recibir información política, el grupo que otorga mayores niveles de credibilidad a este medio; si bien con algunas diferencias entre partidos. Así y dentro de los cinco principales partidos analizados, son los votantes del Partido Socialista Obrero Español (PSOE) e independientemente del tipo de uso, quienes otorgan a este medio mayores niveles medios de credibilidad, 4,62 y 4,60, respectivamente; seguidos por los votantes de Ciudadanos ( $\mathrm{C}^{\prime} \mathrm{s}$ ) en dos de dichos usos, 4,03 y 4,33; y de Unidas Podemos (UP), con un 3,84, 4,59 y 4,36, respectivamente. Estos datos no se corresponden tal y como ya comentamos con el hecho de que sean los votantes que en mayor medida hacen uso de las redes sociales en ambos sentidos, al menos en el caso del PSOE. 
- Usuarios de redes sociales para participar en política

w Usuarios habituales redes sociales
Usuarios de redes sociales para recibir información política

mo Usuarios de redes sociales

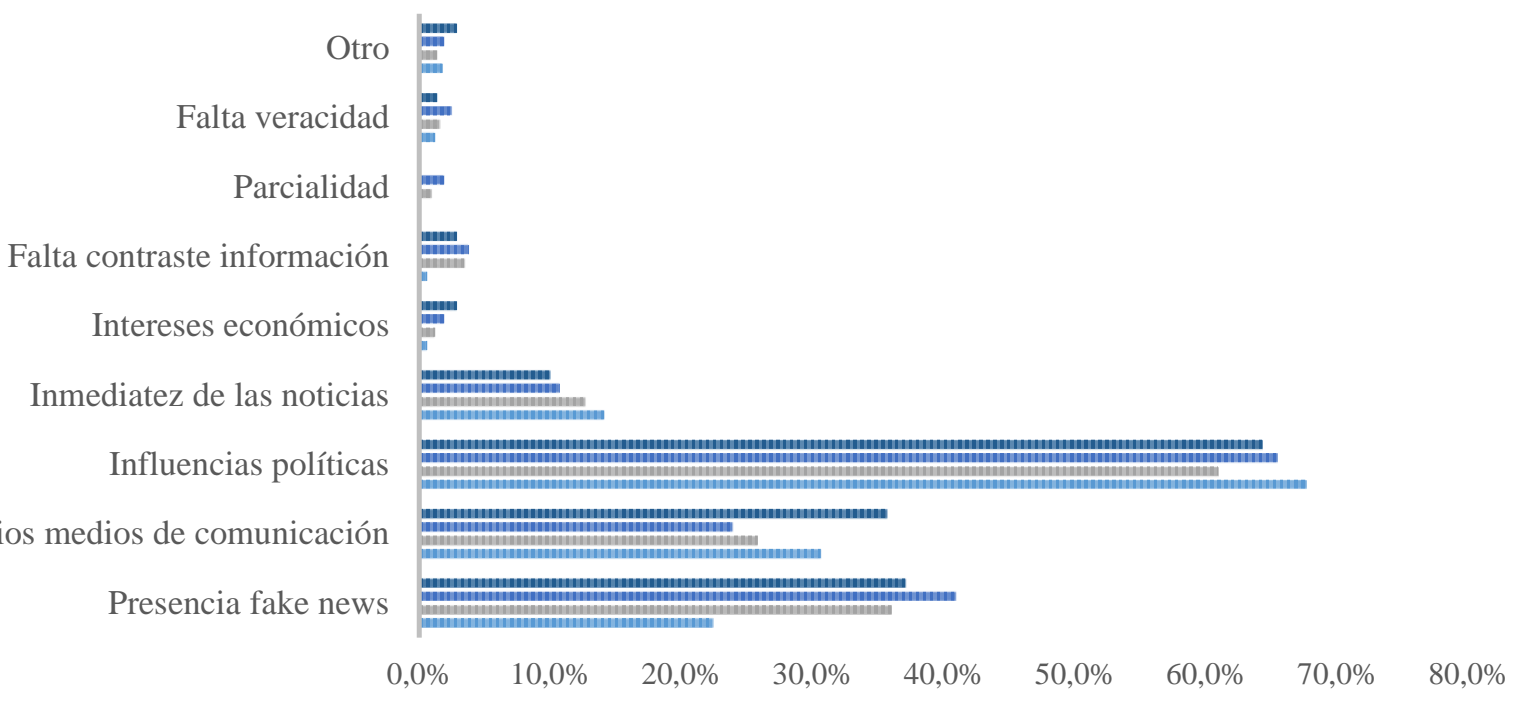

Gráfico 3. Razones del nivel de credibilidad otorgado a las redes sociales según usos de las redes sociales en España

Fuente: elaboración propia a partir de la base de datos EPEE, Feb. 2021 del EIP-USC.

Tabla 4. Tabla de contingencia del nivel de credibilidad otorgado a las redes sociales por los diferentes tipos de usuarios, según recuerdo de voto en elecciones generales de noviembre de 2019 en España

\begin{tabular}{|l|c|c|c|c|}
\hline & $\begin{array}{c}\text { No Usuarios } \\
\text { habituales de } \\
\text { redes sociales }\end{array}$ & $\begin{array}{c}\text { Usuarios } \\
\text { habituales redes } \\
\text { sociales }\end{array}$ & $\begin{array}{c}\text { Usuarios de redes } \\
\text { sociales para } \\
\text { recibir } \\
\text { información } \\
\text { política }\end{array}$ & $\begin{array}{c}\text { Usuarios de redes } \\
\text { sociales para } \\
\text { participar en } \\
\text { política }\end{array}$ \\
\hline PSOE & 3,65 & 4,02 & 4,62 & 4,60 \\
\hline PP & 2,05 & 3,41 & 4,29 & 4,33 \\
\hline UP & 1,88 & 3,84 & 4,59 & 4,36 \\
\hline C's & 1,73 & 4,03 & 4,33 & 3,90 \\
\hline VOX & 1,29 & 3,63 & 4,00 & 5,17 \\
\hline PANE's & 1,60 & 3,80 & 5,33 & 7,00 \\
\hline Otro & - & 3,77 & 5,00 & 4,60 \\
\hline No tenía derecho a voto & - & 5,00 & 5,10 & 1,50 \\
\hline En blanco & 2,50 & 3,00 & 3,80 & 5,00 \\
\hline Nulo & 3,00 & 3,17 & 5,00 & 5,00 \\
\hline Se abstuvo & 1,72 & 3,59 & 5,18 & - \\
\hline No recuerda & 1,33 & 3,20 & 5,00 & 5,00 \\
\hline Nc & 1,63 & 3,60 & 7,25 & 4,46 \\
\hline Total & 2,32 & 3,78 & 4,69 & \\
\hline
\end{tabular}

Fuente: elaboración propia a partir de la base de datos EPEE, Feb. 2021 del EIP-USC. 
Para cerrar esta primera aproximación nos gustaría adentrarnos en el análisis de las emociones que sienten hacia los principales líderes políticos los ciudadanos, en función del uso que realizan de las redes sociales. Del total de las trece emociones incluidas en nuestro estudio demoscópico presentaremos a continuación aquellas que muestran porcentajes de presencia emocional más elevados. Concretamente analizaremos dos emociones negativas referidas al componente emocional de ansiedad, enfado y miedo, las cuales como se avanzó en el apartado 1 han sido ampliamente tratadas por la literatura, y dos emociones positivas, referidas al componente emocional entusiasmo, esperanza y tranquilidad.

En el gráfico 4 se muestra la presencia de enfado y miedo que los ciudadanos expresan hacia los cinco principales líderes en función del uso que realizan de las redes sociales. Como se puede comprobar, en el caso del enfado e independientemente del líder al que hagamos referencia, cuanto mayor es el grado de proactividad en la red, especialmente con fines políticos (informarse de política o participar en política) mayores son los porcentajes de presencia emocional expresados. Especialmente significativas son las diferencias en los casos de P. Sánchez, P. Casado y S. Abascal. Estos datos confirmarían la afirmación, presente en la literatura, respecto del grado de polarización implícito en la participación en las redes sociales, y de cómo en cierta medida, éstas se convierten en "cámaras de eco" que amplifican posiciones y emociones previas, con mayor claridad en el caso de las emociones negativas como el enfado, emoción presente entre quienes tienen una mayor tendencia a asumir situaciones de riesgo, e implicarse, por tanto, en la participación en debates.

No sucede lo mismo como se puede comprobar en el caso del miedo, donde podemos observar cómo son, independientemente del líder al que hagamos referencia, aquellos que utilizan las redes para recibir información política quienes presentan porcentajes de presencia emocional más elevados; siendo especialmente marcadas las diferencias porcentuales en los casos de P. Iglesias y S. Abascal frente a los demás líderes. Sin duda alguna, estos datos concuerdan de nuevo con las posturas defendidas en la literatura abordada, respecto a la búsqueda de mayor cantidad y diversidad de información por parte de quienes sienten miedo, como resultado de la activación del mecanismo de aversión al riesgo y la necesidad de reducir, en la medida de lo posible, sus niveles de incertidumbre. 

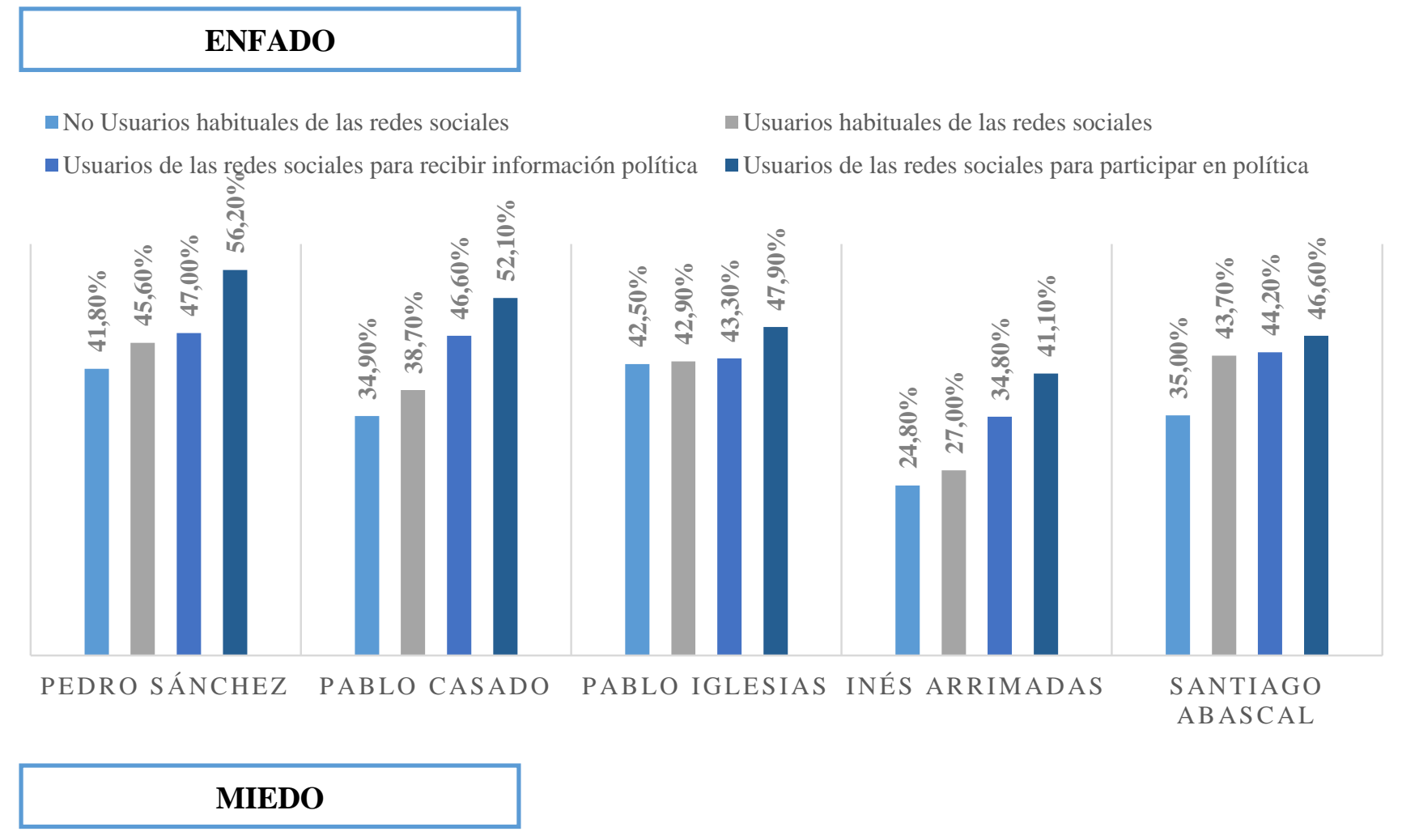

- No Usuarios habituales de las redes sociales usuarios habituales de las redes sociales

-Usuarios de las redes sociales para recibir información política U Usuarios de las redes sociales para participar en política

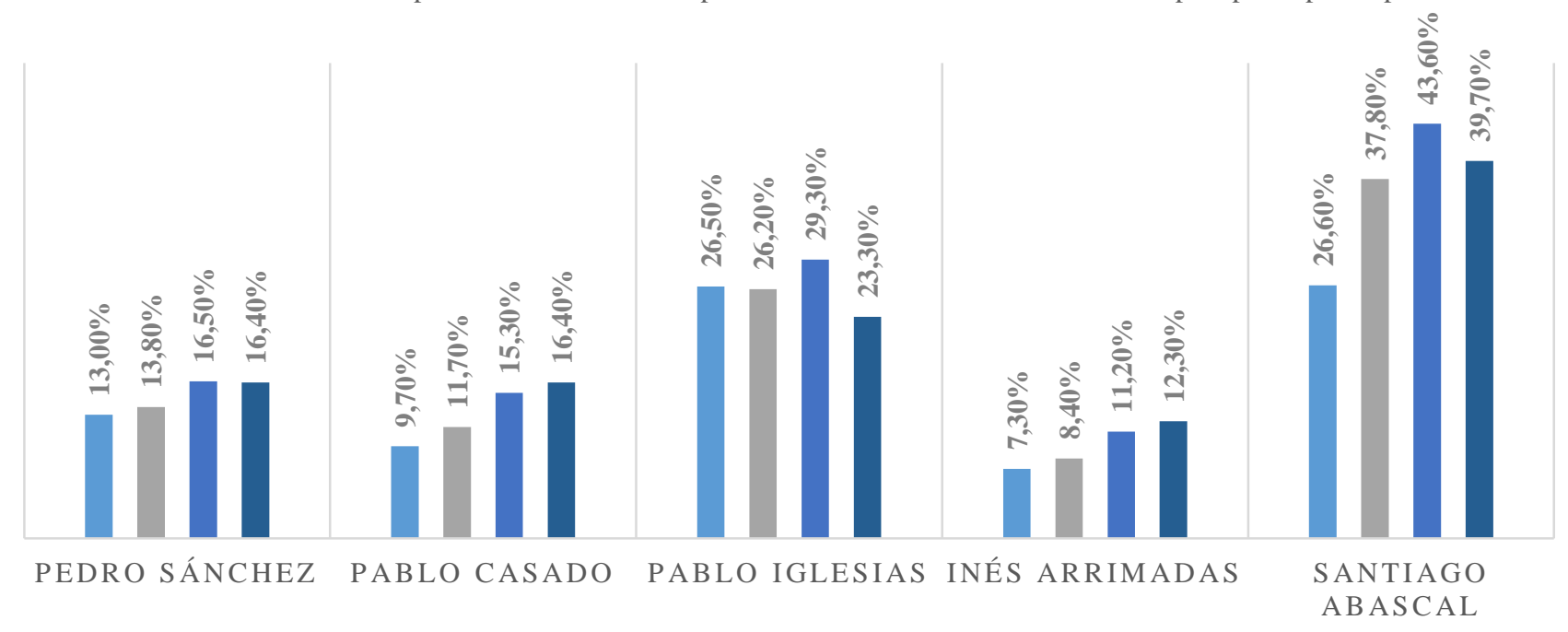

Gráfico 4. Presencia emocional enfado y miedo hacia los principales líderes políticos españoles según uso de las redes sociales

Fuente: elaboración propia a partir de la base de datos EPEE, Feb. 2021 del EIP-USC. 
En contraposición, y si bien las emociones positivas no han sido tratadas con tanto detalle por parte de la literatura ligada a las redes, como es el caso de las emociones negativas, nos gustaría mostrar el caso de dos emociones que presentan importantes niveles de presencia emocional, especialmente en algunos líderes. Son los casos de la esperanza y la tranquilidad (gráfico 5). En el caso de la expresión emocional de esperanza volvemos a encontrarnos con el patrón observado en cuanto al enfado. Así y a medida que aumenta el nivel de proactividad en las redes, aumenta la presencia de esta emoción en todos los líderes, con la única excepción del caso de I. Arrimadas, si bien con pequeñas diferencias. Otra cuestión interesante que señalar en este análisis es el hecho de que con importantes diferencias (hasta más de dieciséis puntos en el caso de algunos grupos) respecto al resto de líderes, P. Sánchez es el líder que mayores niveles de presencia emocional muestra en todos los grupos de usuarios analizados. Como se avanzó en el apartado 1, esta emoción ha sido perfilada como una emoción sostenedora, que facilitaría que las acciones políticas perdurasen en el tiempo. Esta afirmación podría ser aplicada al caso de P. Sánchez, pues en dos de los estudios previos realizados por el EIP-USC, tras las elecciones generales de abril y noviembre de 2019, nos encontramos con este mismo hecho; los elevados niveles de presencia de esperanza hacia este líder entre quienes se informan de política a través de las redes sociales y entre quienes las usan para participar en política.

Finalmente, se presentan los datos de presencia de la emoción tranquilidad hacia los cinco líderes. Como mencionamos en el apartado 1, existe un debate abierto en lo relativo a esta emoción, entendida por algunos no como tal, sino como una actitud. A pesar de ello, tras haberla incluido en nuestros estudios desde el año 2015, hemos comprobado su correcto funcionamiento, por lo que además y dados los porcentajes que presentaba en este caso, hemos considerado oportuno incluirla en el análisis. Tal y como se mencionó, la tranquilidad se ha ligado a la existencia de estados placenteros, por lo que entendemos, además, que puede guardar cierta relación con la presencia de esperanza. Al contrario de lo observado en relación con las anteriores emociones, nos encontramos con patrones menos claros en base a tipos de usuarios. En cuanto a los líderes, es P. Sánchez, de igual forma que sucedía con la esperanza, el líder hacia el cual los ciudadanos muestran mayores niveles de presencia emocional, independientemente del uso que realicen de las redes, seguido por P. Iglesias, aunque ya con una importante diferencia porcentual. En cuanto a los usos, encontramos patrones inversos, con claridad en los casos de P. Casado y S. Abascal respecto al resto de líderes. En el caso del primero la tranquilidad aumenta cuanto menor es la presencia en la red, mientras que en el caso del segundo aumenta, a medida que la implicación política en la red lo hace. Patrón este último que observamos también en el caso de P. Iglesias. En el supuesto de P. Sánchez son los usuarios habituales, y aquellos que utilizan las redes para recibir información política quienes muestran mayores niveles de presencia de esta emoción; algo similar a lo que sucede en el caso de I. Arrimadas. 


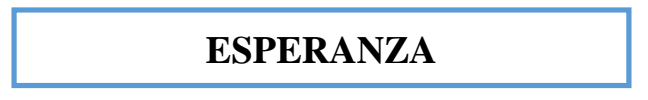

- No Usuarios habituales de las redes sociales

n Usuarios habituales de las redes sociales

- Usuarios de las redes sociales para recibir información política

- Usuarios de las redes sociales para participar en política
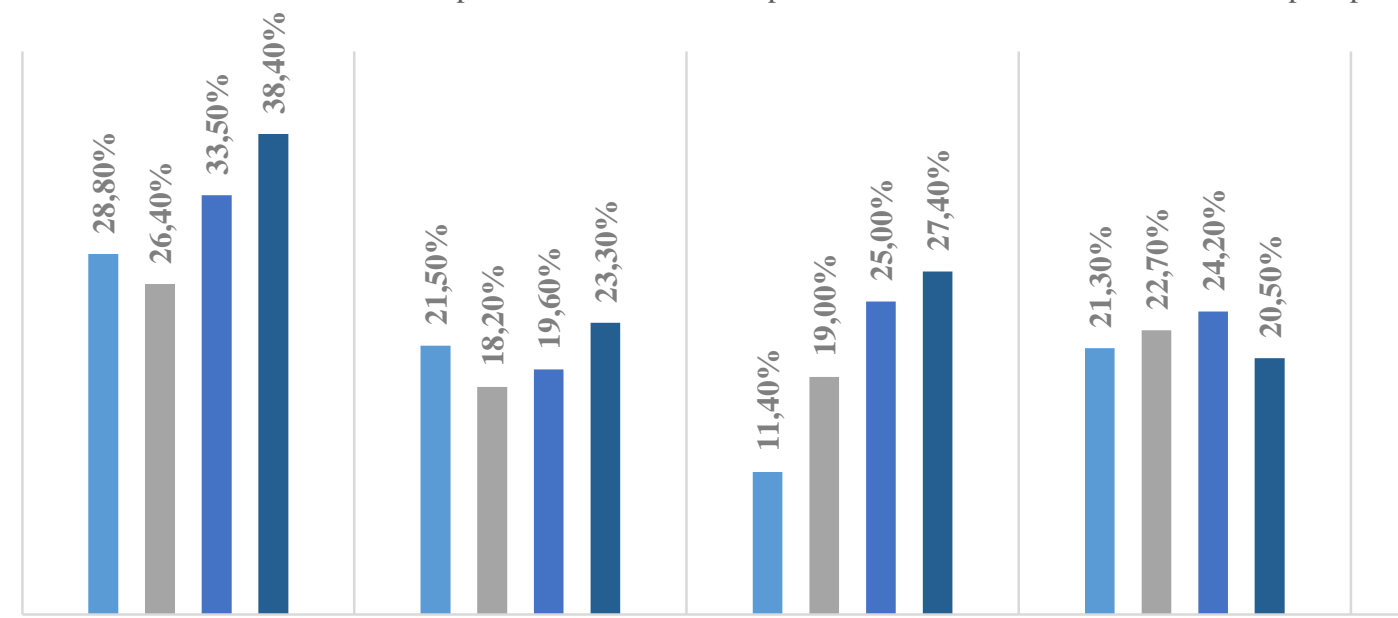

PEDRO SÁNCHEZ PABLO CASADO

PABLO IGLESIAS INÉS ARRIMADAS

SANTIAGO AB ASCAL

TRANQUILIDAD

- No Usuarios habituales de las redes sociales

- Usuarios habituales de las redes sociales

- Usuarios de las redes sociales para recibir información política — Usuarios de las redes sociales para participar en política

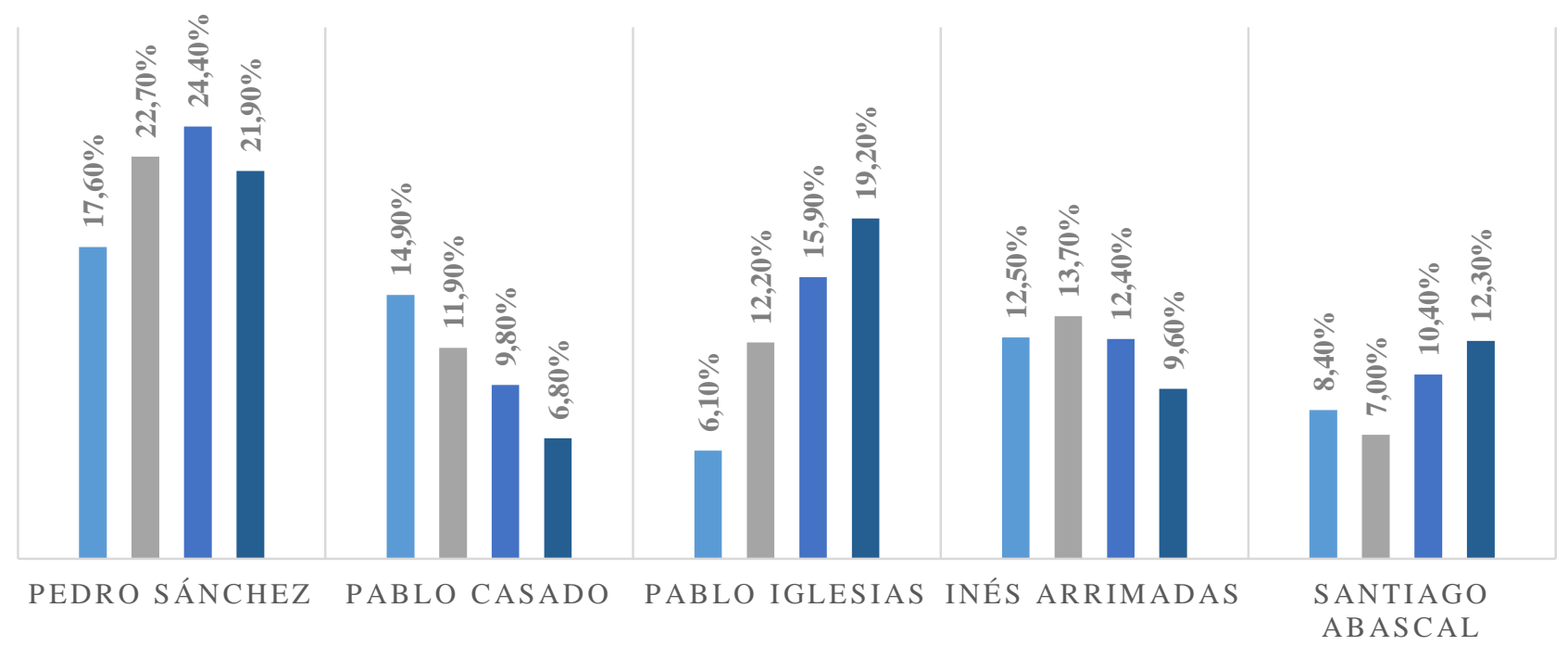

Gráfico 5. Presencia emocional esperanza y tranquilidad hacia los principales líderes políticos españoles según uso de las redes sociales

Fuente: elaboración propia a partir de la base de datos EPEE, Feb. 2021 del EIP-USC.

\subsection{Análisis de escalamiento óptimo del uso de las redes sociales}

Hemos considerado pertinente cerrar este trabajo con un análisis de interdependencia entre las principales variables objeto de esta investigación: los diferentes usos que los ciudadanos realizan de las redes sociales, el posicionamiento político de aquellos y la presencia emocional que expresan hacia los principales líderes, agentes primordiales de la competición política. Para ello hemos 
procedido en el primer caso dibujando un análisis de correspondencias simple de la relación existente entre el voto a las distintas formaciones y los tipos de usos que se realizan de las redes por parte de la ciudadanía; y en el segundo caso, a través del planteamiento de cuatro análisis de escalamiento óptimo, uno para cada una de las emociones analizadas en relación con los diferentes usos de las redes sociales 6 .

Comenzamos con la presentación en el gráfico 6 del análisis de correspondencias simple de la relación existente entre los diferentes usos de las redes sociales y el voto en las elecciones generales de noviembre de 2019. Se observa una relación entre ambas variables, tal y como avanzaba el análisis descriptivo. Así, aquellos que se informan de política a través de las redes mantienen relación con el hecho de ser votantes de UP, al tiempo que quienes las utilizan para participar se relacionan con el hecho de votar a VOX. Por su parte, los partidos tradicionales, PSOE y PP, se muestran más próximos de perfiles con un menor uso político de las redes. Además, como podemos observar, quien es usuario de las redes sociales, pero no con fines políticos guarda relación con el perfil de quienes no son usuarios. Sin duda esto tiene un importante valor respecto a lo que durante tiempo se ha defendido en relación con el uso de las redes sociales, no es importante la presencia en ellas, sino la presencia con fines o motivaciones de carácter político.

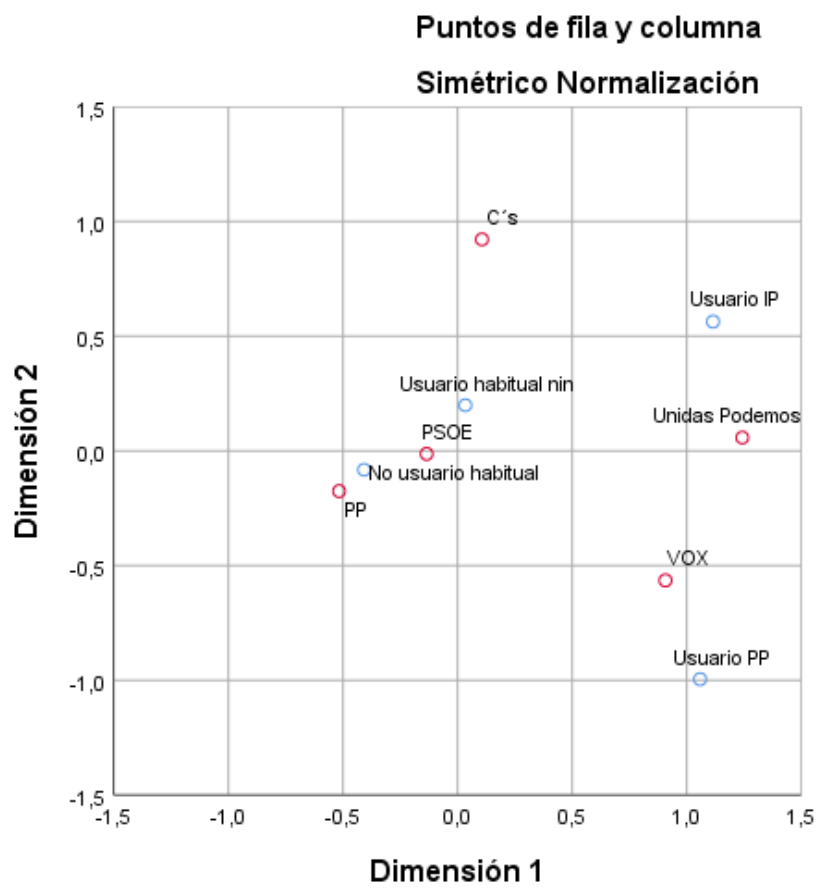

Tipos usos redes sociales

OVoto_nov195

Gráfico 6. Análisis de correspondencias simple de los usos de las redes sociales y el voto en las elecciones generales de noviembre de 2019

Fuente: elaboración propia a partir de la base de datos EPEE, Feb. 2021 del EIP-USC.

\footnotetext{
${ }^{6}$ Para la realización de estos dos análisis hemos procedido a la creación de una variable en la que se han unificado, a partir de las variables originales, los diferentes tipos de usos que, de las redes realiza la ciudadanía: no usuarios, usuarios habituales, usuarios para informarse de política y usuarios de redes sociales para participar en política.
} 


\section{ENFADO}

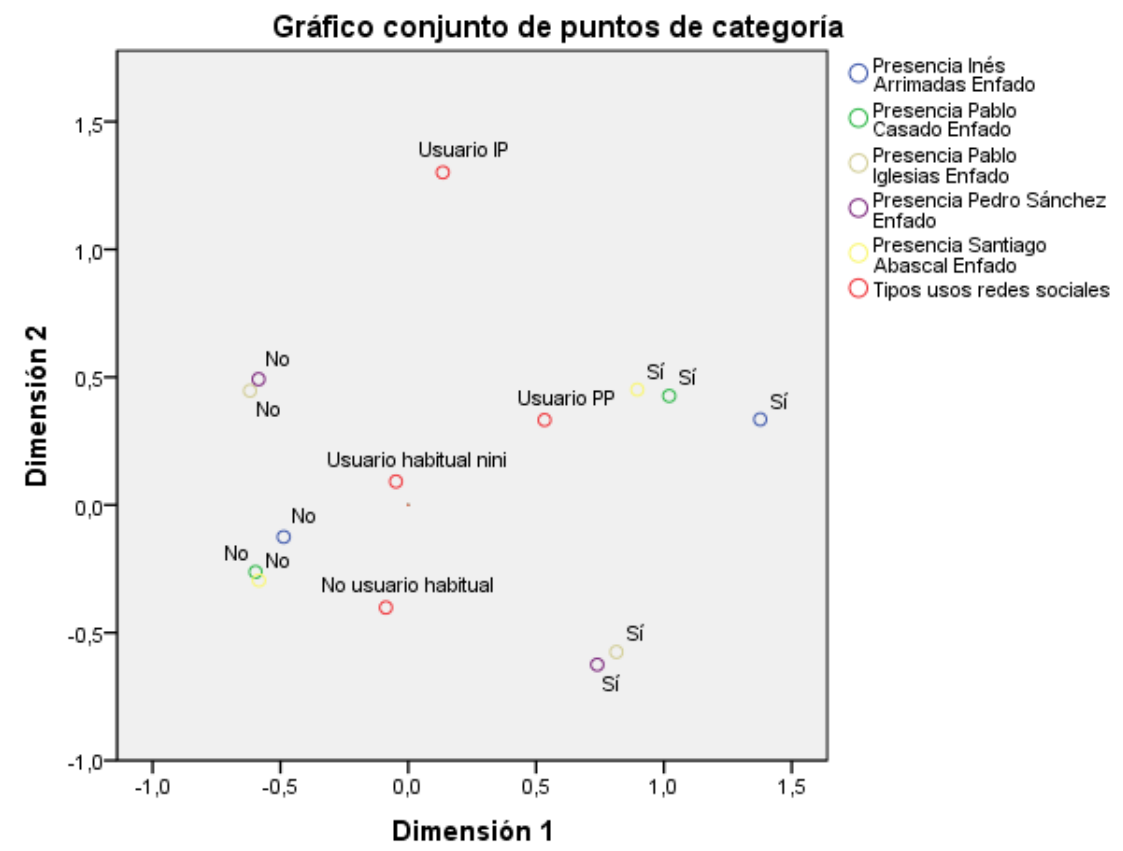

Normalización de principal de variable.

\section{MIEDO}

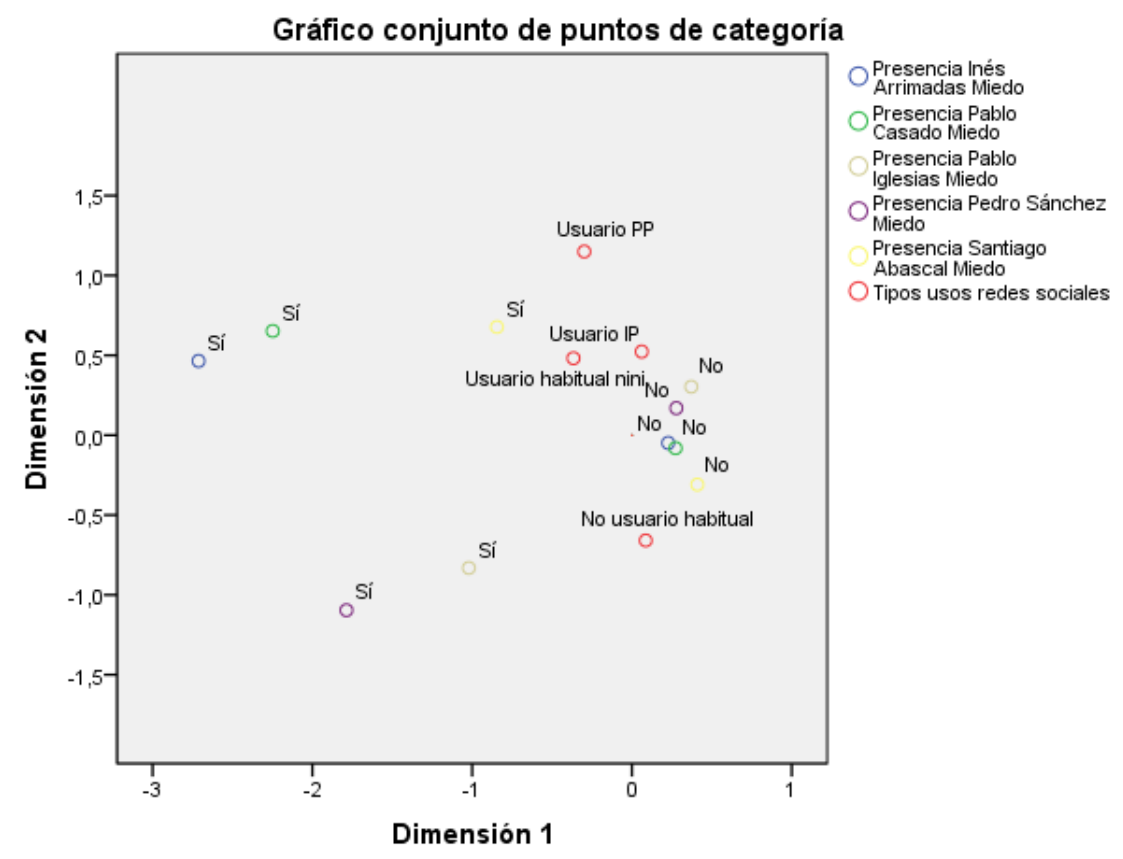

Normalización de principal de variable.

Gráfico 7. Análisis de correspondencias múltiple de la presencia emocional de enfado y miedo y los usos de las redes sociales

Fuente: elaboración propia a partir de la base de datos EPEE, Feb. 2021 del EIP-USC. 
En el gráfico 7 se muestran los resultados gráficos del escalamiento óptimo o análisis de correspondencias múltiples realizado para la presencia emocional de enfado y miedo hacia los cinco líderes políticos y los usos de las redes sociales por parte de los ciudadanos.

En el caso de la presencia emocional de enfado hacia los líderes en relación con el uso de las redes que realizan los ciudadanos, se puede comprobar que existe asociación, tal y como ya avanzaba el análisis descriptivo expuesto en el apartado anterior, entre el hecho de ser usuario de las redes para participar en política y el expresar enfado, especialmente hacia los líderes de los partidos de derecha y extrema derecha: I. Arrimadas, P. Casado y S. Abascal. En contraposición, quienes no usan las redes con fines políticos, mantienen una relación con el hecho de no sentir enfado hacia el conjunto de los cinco líderes. De nuevo, estos datos de asociación fortalecen los hallazgos que la literatura sobre emociones y comunicación ya ha puesto de manifiesto, y que ampliamente hemos comentado.

En cuanto a la presencia emocional de miedo hacia los líderes en relación con el uso que se realiza de las redes, tal y como se aprecia en el segundo gráfico de conjunto de puntos, el hecho de no sentir miedo hacia los líderes guarda mayor relación con el hecho de no usar las redes para informarse. Quien las utiliza busca en ellas información que tienda a reducir su incertidumbre y en consecuencia, el miedo hacia hechos, acciones o actores.

En el gráfico 8 se muestran los niveles de relación del análisis de correspondencias múltiple realizado para la presencia de esperanza y tranquilidad en función de los usos que se realizan de las redes. A la vista del mapeado en lo que a la esperanza se refiere, observamos como la presencia de esta emoción hacia P. Sánchez guarda una importante relación con el hecho de usar las redes para informarse o recibir información política, pero en mayor medida con el hecho de usar las redes para participar en política, cuestión que ya avanzaba el descriptivo. También se daría este patrón, pero en menor medida, con relación a la presencia de esperanza hacia el resto de los líderes. En contraposición, el hecho de no presentar esta emoción guarda relación con el hecho de no ser usuario de redes o bien con el hecho de ser usuario, pero no con motivaciones políticas de las mismas. Esto sin duda confirma lo ya mencionado en relación con el análisis de correspondencias simples, y el similar perfil existente entre estos dos tipos de usuarios de redes.

Para terminar y en lo que al análisis de correspondencias múltiples de la presencia de tranquilidad en relación con los usos de las redes sociales se refiere, el patrón no es demasiado claro, cuestión que también avanzaba el análisis descriptivo previo. Así y si bien pareciera existir cierta relación entre realizar un uso político de las redes con la presencia emocional hacia P. Sánchez, y en menor medida hacia P. Iglesias, no sucede así con otros líderes. En cuanto a la no presencia de esta emoción, sí observamos con bastante claridad su relación con el hecho de no ser usuario de redes o bien ser usuario habitual de este medio de comunicación, pero sin fines o implicaciones de carácter político. 


\section{ESPERANZA}

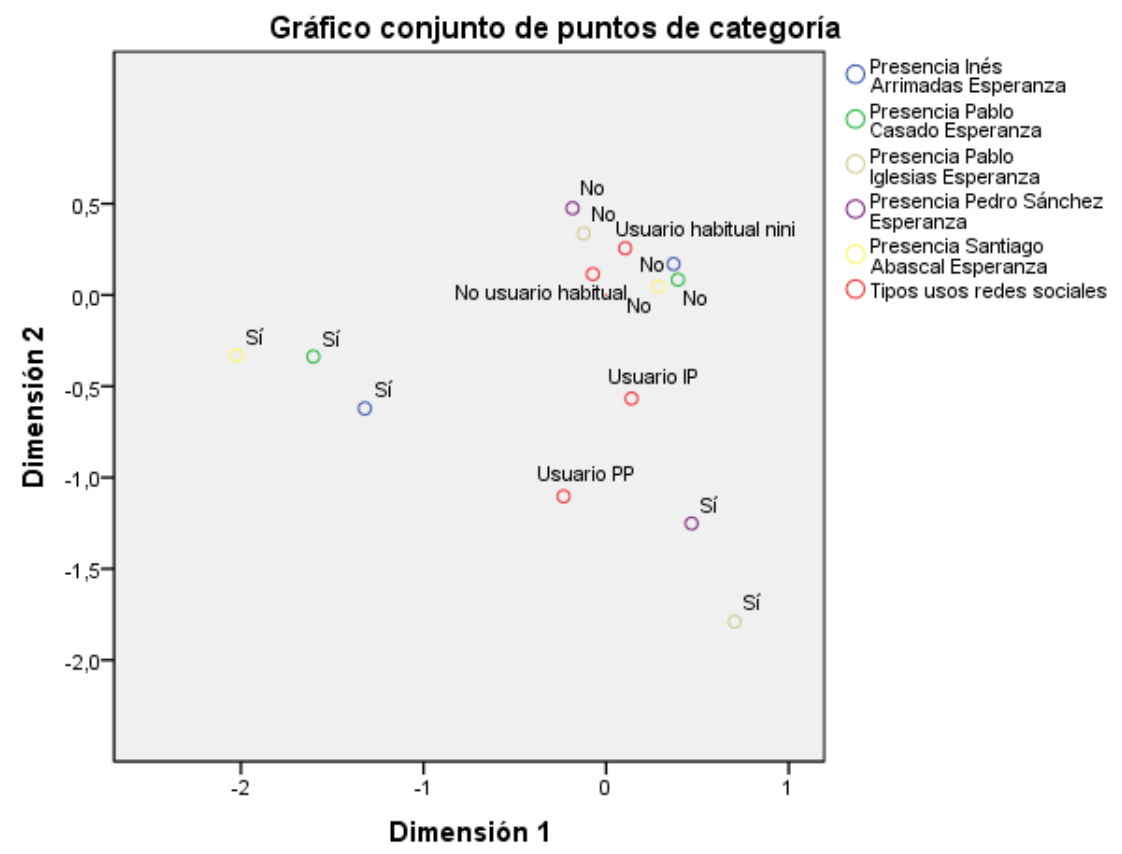

Normalización de principal de variable.

\section{TRANQUILIDAD}

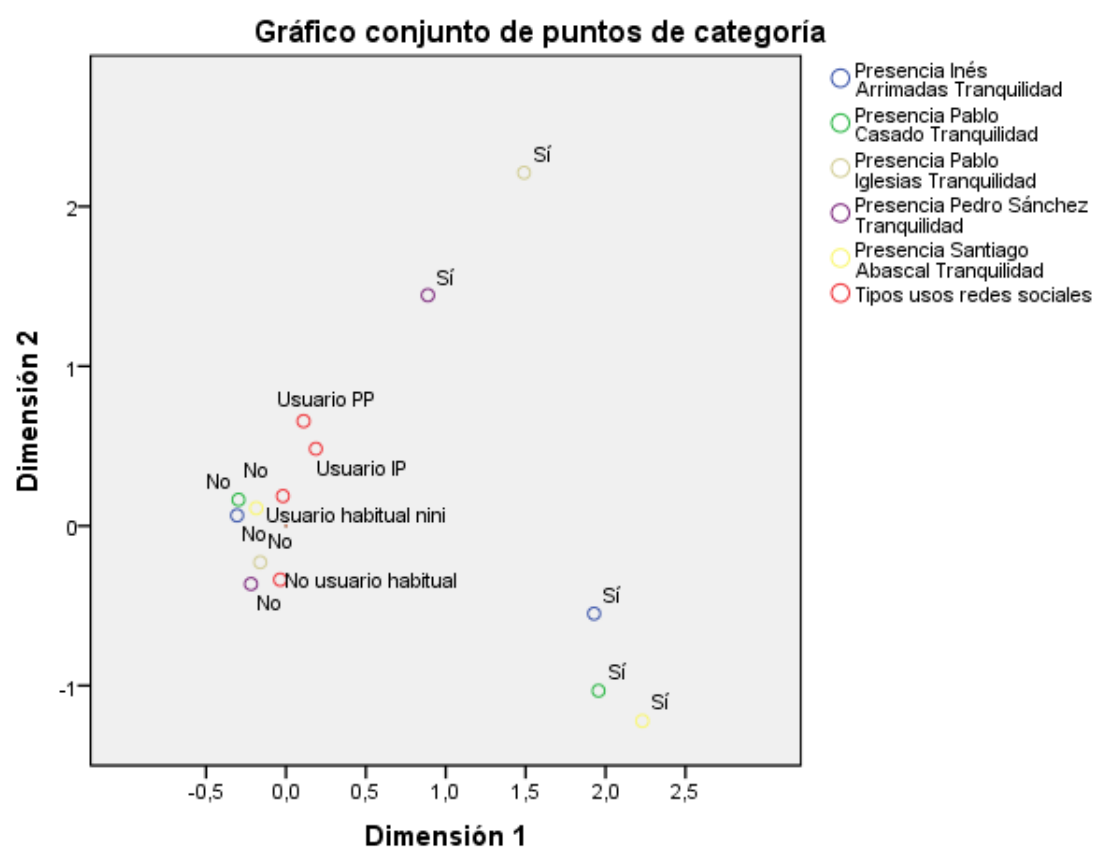

Normalización de principal de variable.

Gráfico 8. Análisis de correspondencias múltiple de la presencia emocional de esperanza y tranquilidad y los usos de las redes sociales

Fuente: elaboración propia a partir de la base de datos EPEE, Feb. 2021 del EIP-USC. 


\section{Conclusiones}

Los resultados presentados en esta investigación muestran la relación que el diferente uso de las redes sociales pueda tener con el posicionamiento político de los usuarios, así como con las emociones que puedan sentir hacia los líderes políticos. Sin lugar a duda, estos primeros hallazgos son de gran valor, pues confirman las hipótesis inicialmente planteadas, al tiempo que mantienen algunas líneas de investigaciones previas, en especial en lo que a la presencia de las emociones se refiere.

A la vista del análisis podemos afirmar que el uso con fines políticos de las redes bien sea para recibir información política o para participar políticamente, está mediatizado por el posicionamiento político de los ciudadanos (H1), cuestión que corroboran tanto el análisis descriptivo como el análisis de correspondencias realizado. Una afirmación que ratifica el nivel de politización existente en las redes, cuestión que ya ha sido puesta en valor con el análisis de otros medios de comunicación offline. Este hecho no sólo se refleja en el tipo de uso que se realiza de las mismas, sino también en las redes concretas que se utilizan en función del posicionamiento político de los actores (H2), existiendo una pauta diferencial marcada no tanto por el posicionamiento político en sí mismo, sino por la intensidad del mismo, de forma que los votantes de UP y VOX mostrarían un uso similar de las redes, más equilibrado pero con especial atención a Twitter, una de las redes sociales más politizada y polarizada, frente a los partidos centrípetos, que mostrarían un patrón común más volcado en las redes que han sido definidas como menos polarizadas, Facebook o Instagram.

Finalmente, el análisis realizado confirma nuestra tercera hipótesis. Cuanta mayor es la proactividad en el uso político de las redes sociales mayor es la expresión emocional que hacia los líderes políticos expresan los ciudadanos, con especial atención a las emociones negativas como enfado y miedo. Estos hallazgos se suman a los ya existentes respecto a la importancia de las redes como "cámaras de eco" que amplifican los debates que en ellas se producen, en una suerte de "espiral emocional". Una emotividad que en el caso de quienes sienten enfado los llevaría a utilizarlas como reforzadores de sus posicionamientos previos, y entre quienes sienten miedo, a convertirlas en espacios en los que encontrar información diversa que les permita reducir sus niveles de incertidumbre. Consideramos oportuno seguir profundizando en un futuro en este tipo de análisis, con especial énfasis en la posibilidad de determinar cuáles son los elementos que propiciarían el surgimiento de dichas expresiones emocionales y si las mismas varían o no en función del momento político (período electoral o no electoral).

\section{Bibliografía}

Averill, J. R., y Thomas-Knowles, C. (1991). Emotional creativity. En: K. T. Strongman (ed.), International review of studies on emotion, 269-299. Londres: Wiley.

Bail, Ch. A. (2016). Emotional feedback and the viral spread of social media messages about Autism spectrum disorders. American Journal of Public Health, 106, 1173 - 1180. https://doi.org/10.2105/AJPH.2016.303181

Botvinick, M., y Braver, T. (2015). Motivation and cognitive control: from behavior to neural mechanism. Annual Review of Psychology, 66, 83-113. https://doi.org/10.1146/annurev-psych$\underline{010814-015044}$ 
Bode, L. (2016). Political news in the news feed: Learning politics from social media. Mass Communication and Society, 19 (1), 24 - 48. https://doi.org/10.1080/15205436.2015.1045149

Brady, W. J., Wills, J. A., Jost, J. T., Tucker, J. A y Van Bavel, J. J. (2017). Emotion shapes the diffusion of moralized content in social networks. Proceedings of the National Academy of Sciences, 114 (28), 7313 - 7318. https://doi.org/10.1073/pnas.1618923114

Casero-Ripollés, A. (2018). Investigación sobre información política y redes sociales: puntos clave y retos de futuro. El Profesional de la Información, 27 (5), 964 - 974. https://doi.org/10.3145/epi.2018.sep.01

Colleoni, E., Rozza, A. y Arvidsson, A. (2014). Echo chamber or public sphere? Predicting political

orientation and measuring political homophily in Twitter using big data. Journal of Communication, 64 (2), 317-332. https://doi.org/10.1111/jcom.12084

Cordaro, D. T., Brackett, M., Glass, L. y Anderson, C. L. (2016). Contentment: perceived completeness across cultures and traditions. Review of General Psychology, 20 (3), 221-235. https://doi.org/10.1037/gpr0000082

Del Vicario, M., Bessi, A., Zollo, F., Petroni, F., Scala, A., Caldarelli, G. y Quattrociocchi, W. (2015). Echo chambers in the age of misinformation. Computer and Society. https://arxiv.org/abs/1509.00189

Del Vicario, M., Zollo, F., Caldarelli, G., Scala, A. y Quattrociocchi, W. (2017). Mapping social dynamics on Facebook: The Brexit debate. Social Networks, 50, 6-16. https://doi.org/10.1016/j.socnet.2017.02.002

Elster, J. (2002). Alquimias de la mente. La racionalidad y las emociones. Barcelona: Paidós.

Fredrickson B. L. (1998). What Good Are Positive Emotions? Review of General Psychology: Journal of Division 1, of the American Psychological Association, 2 (3): 300-319. https://doi.org/10.1037/1089-2680.2.3.300

Garrett, R. K. (2009). Politically motivated reinforcement seeking: reframing the selective exposure debate. Journal of Communication, 59: 676-699. doi:10.1111/j.1460-2466.2009.01452.x

Gil de Zúñiga, H., Molyneux, L. y Zheng, P. (2014). Social media, political expression, and political participation: Panel analysis of lagged and concurrent relationships. Journal of Communication, 64, (4), 612 - 634. https://doi.org/10.1111/jcom.12103

Harré, R. (1986). The social construction of emotions. New York: Basil Blackwell.

Hasell, A. y Weeks, B. E. (2016). Partisan provocation: The role of partisan news use and emotional responses in political information sharing in social media. Human Communication Research, 42, 641 - 661. https://doi.org/10.1111/hcre.12092

Helmond, A. (2015). The plataformization of the web. Making web data platform ready. Social Media + Society, 1-11. https://journals.sagepub.com/doi/10.1177/2056305115603080 
Jones, P. E., Hoffman, L. H. y Young, D. G. (2013). Online emotional appeals and political participation: The effect of candidate affect on mass behavior. New Media \& Society, 15: 11321150. https://doi.org/10.1177/1461444812466717

Knoll, J., Matthes, J. y Heiss, R. (2020). The social media political participation model: A goal systems theory perspective. Convergence, 26, $\quad(1), \quad 135 \quad$ - 156. https://doi.org/10.1177/1354856517750366

Kramer, A. D., Guillory, J. E. y Hancock, J. T. (2014). Experimental evidence of massive-scale emotional contagion through social networks. Proceedings of the National Academy of Sciences of the United States of America, 111, 8788 - 8790. https://doi.org/10.1073/pnas.1320040111

Kwak, H., Lee, Ch., Park, H. y Moon, S. (2010). What is Twitter, a social network or a news media?. Proceedings of the 19th International Conference on World Wide Web, 591 - 600. https://doi.org/10.1145/1772690.1772751

Lazarus, R. S. (1999). Hope: an emotion and a vital coping resource against despair. Social Research, 66 (2): 653-678.

Lerner, J. S. y Keltner, D. (2001). Fear, anger, and risk. Journal of Personality and Social Psychology, 81, 146 - 159. https://doi.org/10.1037//O022-3514.81.1.146

McPherson, M., Smith-Lovin, L. y Cook, J. M. (2001). Birds of a feather: Homophily in social networks. Annual Review of Sociology, 27(8), 415-444. https://doi.org/10.1146/annurev.soc.27.1.415

Marcus, G. E. (2019). How fear and anger impact democracy. Democracy Papers Essay.

Marcus, G. E., Neuman, R. y Mackuen, M. (2000). Affective intelligence and political judgement. Chicago: Chicago University Press.

Marcus, G. E., Neuman, R. W. y MacKuen, M. B. (2017). Measuring emotional response: comparing alternative approaches to measurement. Journal of Political Science Research and Methods, 5 (4), 733 - 754. https://doi.org/10.1017/psrm.2015.65

Marcus, G. E., Valentino, N. A., Vasilopoulos, P. y Foucault, M. (2019). Applying the theory of Affective Intelligence to support for authoritarian policies and parties. Advances in Political Psychology, 40 (S1), 109 - 139. https://doi.org/10.1111/pops.1257

Norris, P. (2001). Digital Divide: Civic Engagement, Information Poverty, and the Internet Worldwide (Communication, Society and Politics). Cambridge: Cambridge University Press. doi:10.1017/CBO9781139164887

Neuman, W. R., Marcus, G. E. y Mackuen, M. B. (2018). Hardwired for news: Affective Intelligence and political attention. Journal of Broadcasting y Electronic Media, 62 (4), 614 - 635. https://doi.org/10.1080/08838151.2018.1523169

Oñate, P. y López-López, P. C. (2020). Información y participación en redes sociales y voto a VOX. En: E. Jaráiz, A. Cazorla y M. Pereira (Eds.). El auge de la extrema derecha en España. 591 600. Valencia: Tirant lo Blanch,. 
Serrano-Puche, J. (2016). Internet y emociones: nuevas tendencias en un campo de investigación emergente. Comunicar: Revista Científica de Comunicación y Educación, 24 (46), 19 - 26. https://doi.org/10.3916/C46-2016-02

Shahin, S., Saldaña, M. y Gil de Zúñiga, H. (2020). Peripheral elaboration model: The impact of incidental news exposure on political participation. Journal of Information Technology \& Politics, 1 - 16. https://doi.org/10.1080/19331681.2020.1832012

Stier, S., Bleier, A., Lietz, H. y Strohmaier, M. (2018). Election campaigning on social media: Politicians, audiences, and the mediation of political communication on Facebook and Twitter. Political Communication, 35 (1), 50 -74. https://doi.org/10.1080/10584609.2017.1334728

Sunstein, C. R. (2001). Republic.com. Princeton, NJ: Princeton University Press.

Vasilopoulos, P., Marcus, G. E. y Foucault, M. (2018). Emotional responses to the Charlie Hebdo attack: Addressing the authoritarianism puzzle. Political Psychology, 39 (3), 557 - 575. https://doi.org/10.1111/pops.12439

Vasilopoulos, P., Marcus, G. E., Valentino, N. y Foucault, M. (2018). Fear, anger, and voting for the far right: Evidence from the November 13, 2015 Paris terror attacks. Political Psychology, 40 (4), 679 - 704. https://doi.org/10.1111/pops.12513

Wollebæk, D., Karlsen, R., Steen-Johnsen, K. y Enjolras, B. (2019). Anger, Fear, and Echo Chambers: The Emotional Basis for Online Behavior. Social Media + Society, 1-14. https://doi.org/10.1177/2056305119829859

Yarchi, M., Baden, Ch. y Kligler-Vilenchik, N. (2020). Political polarization on the digital sphere: A cross-platform, over-time analysis of interactional, positional, and affective polarization on social media. Political Communication, 98 - 139. https://doi.org/10.1080/10584609.2020.1785067

\section{AUTORES:}

\section{José Manuel Rivera Otero}

José Manuel Rivera es profesor titular de Ciencia Política y de la Administración en la USC. Director del Máster Universitario en Marketing, Consultoría y Comunicación Política de la USC. Entre sus recientes publicaciones destacan: Rivera, J. M., Castro, P. y Mo, D. (2021). Emociones y extrema derecha: el caso de VOX en Andalucía. Revista Española de Investigaciones Sociológicas (aceptado, fecha de publicación prevista: 10/21). Jaráiz, E., Pereira, María y Rivera, José M. (2021). Un análisis emocional de las respuestas de los electores a la comunicación online de los candidatos en campaña. Análisis comparado de las elecciones generales de 2019 en Bolivia y España. Journal of Iberian and Latin American Research. Rivera, J.M., Montabes, J. y Lagares, N. (eds.). (2016). Cataluña en proceso: las elecciones autonómicas de 2015. Valencia: Tirant Lo Blanch.

josemanuel.rivera@usc.es

Orcid ID: https://orcid.org/0000-0003-0306-1768

\section{Nieves Lagares Diez}

Nieves Lagares es profesora titular de Ciencia Política y de la Administración en la USC. Doctora en Ciencia Política por la misma universidad (1997). Entre sus recientes publicaciones destacan: Pereira 
López, M.; Mo Groba, D. y N. Lagares Diez (2020). Información offline y online en campaña: uso de las redes sociales en las elecciones catalanas 2017. Revista Ibérica de Sistemas e Tecnologías da Informaçao, E26 (2): 229-241. Lagares, N., Pereira M. y Rivera J. M. (2018). "Diferencias y homogeneidades en el voto a Podemos y sus confluencias". En: F.J. Llera, J. Montabes y M. Baras (ed.). Las elecciones generales de 2015 y 2016. Madrid: CIS. Máiz, R., Lagares N. y Pereira M. (2018). "Catalonia: Federalism or Secession?”. Open Journal of Political Science, 8 (4); Jaráiz, E., N. Lagares y X.L. Barreiro (2017). "Condiciones y razones del procés”. Araucaria, 19 (38). mnieves.lagares@usc.es

Orcid ID: https://orcid.org/0000-0001-5304-0581

\section{María Pereira López}

María Pereira es profesora de Ciencia Política en la USC desde 2015. Licenciada en Ciencia Política y de la Administración y Doctora en Ciencia Política por la citada universidad. Entre sus publicaciones destacan Jaráiz, E., Pereira, M. y Rivera, José M. (2021). Un análisis emocional de las respuestas de los electores a la comunicación online de los candidatos en campaña. Análisis comparado de las elecciones generales de 2019 en Bolivia y España. Journal of Iberian and Latin American Research (JILAR). Jaráiz, E., Lagares, N. y Pereira, M. (2020). Emociones y decisión de voto. Los componentes de voto en las elecciones generales de 2016 en España. Revista Española de Investigaciones Sociológicas, 170: 115-136. Pereira, M.. Mo, D. y Lagares, N. (2020). Información offline y online en campaña: uso de las redes sociales en las elecciones catalanas 2017. Revista Ibérica de Sistemas e Tecnologías da Informaçao, E26 (2): 229-241.

maria.pereira.lopez@usc.es

Orcid ID: https://orcid.org/0000-0002-2802-9396

\section{Erika Jaráiz Gulías}

Erika Jaráiz es Doctora en Ciencia Política y profesora del Departamento Ciencia Política y Sociología de la USC. Pertenece al Equipo de Investigaciones Políticas. Entre sus publicaciones más recientes destacan: Jaráiz, E., Pereira, M. y Rivera, José M. (2021). Un análisis emocional de las respuestas de los electores a la comunicación online de los candidatos en campaña. Análisis comparado de las elecciones generales de 2019 en Bolivia y España. Journal of Iberian and Latin American Research. Jaráiz, E., Lagares, N. y Pereira, M. (2020). Emociones y decisión de voto. Los componentes de voto en las elecciones generales de 2016 en España. Revista Española de Investigaciones Sociológicas, 170: 115-136. Jaráiz, E., López, P.C. y Bastos, M. (2020). Economía, política social y Twitter: análisis de las emociones negativas en cuatro elecciones presidenciales latinoamericanas a través del LIWC. Revista Ibérica de Sistemas y Tecnologías de la Información, E26: 280-292.

erika.jaraiz@usc.es

Orcid ID: https://orcid.org/0000-0003-2382-6713 
RLCS, Revista Latina de Comunicación Social, 79, 73-98

[Investigación] DOI: 10.4185/RLCS-2021-1518| ISSN 1138-5820| Año 2021

\section{Anexos}

Tabla 5. Frecuencia de uso de las de redes sociales según recuerdo de voto en las elecciones generales de noviembre de 2019

\begin{tabular}{|c|c|c|c|c|c|c|c|c|c|c|c|c|c|c|c|}
\hline & \multicolumn{13}{|c|}{ Recuerdo de voto elecciones generales noviembre 2019} & \multirow[b]{2}{*}{ Total } \\
\hline & & PSOE & $\mathrm{PP}$ & UP & $C^{\prime} s$ & VOX & PANE's & Otro & $\begin{array}{c}\text { No tenía } \\
\text { derecho } \\
\text { a voto }\end{array}$ & $\begin{array}{c}\text { En } \\
\text { blanco }\end{array}$ & Nulo & $\begin{array}{c}\mathrm{Se} \\
\text { abstuvo }\end{array}$ & $\mathrm{Nr}$ & $\mathrm{Nc}$ & \\
\hline \multirow{7}{*}{$\begin{array}{l}\text { Frecuencia } \\
\text { de uso de } \\
\text { las redes } \\
\text { sociales }\end{array}$} & Todos o casi todos los días & $69,6 \%$ & $73,9 \%$ & $78,7 \%$ & $68,4 \%$ & $80,6 \%$ & $74,5 \%$ & $84,6 \%$ & $77,8 \%$ & $42,9 \%$ & $91,7 \%$ & $71,7 \%$ & $100,0 \%$ & $75,0 \%$ & $73,6 \%$ \\
\hline & 4 o 5 días por semana & $6,5 \%$ & $4,3 \%$ & $4,3 \%$ & $2,6 \%$ & $2,8 \%$ & & $15,4 \%$ & & $28,6 \%$ & & $1,9 \%$ & & $10,0 \%$ & $4,9 \%$ \\
\hline & 2 o 3 días por semana & $4,3 \%$ & $2,9 \%$ & & $7,9 \%$ & $2,8 \%$ & $4,3 \%$ & & & $7,1 \%$ & & $1,9 \%$ & & $5,0 \%$ & $3,3 \%$ \\
\hline & Sólo los fines de semana & $0,7 \%$ & & & & & & & & & & & & & $0,2 \%$ \\
\hline & De vez en cuando & $18,1 \%$ & $18,8 \%$ & $17,0 \%$ & $15,8 \%$ & $13,9 \%$ & $17,0 \%$ & & $16,7 \%$ & $14,3 \%$ & $8,3 \%$ & $11,3 \%$ & & $10,0 \%$ & $15,3 \%$ \\
\hline & Nunca o casi nunca & $0,7 \%$ & & & $5,3 \%$ & & $2,1 \%$ & & $5,6 \%$ & $7,1 \%$ & & $13,2 \%$ & & & $2,5 \%$ \\
\hline & $\mathrm{Ns} / \mathrm{Nc}$ & & & & & & $2,1 \%$ & & & & & & & & $0,2 \%$ \\
\hline \multicolumn{2}{|l|}{ Total } & $100,0 \%$ & $100,0 \%$ & $100,0 \%$ & $100,0 \%$ & $100,0 \%$ & $100,0 \%$ & $100,0 \%$ & $100,0 \%$ & $100,0 \%$ & $100,0 \%$ & $100,0 \%$ & $100,0 \%$ & $100,0 \%$ & $100,0 \%$ \\
\hline
\end{tabular}

Fuente: elaboración propia a partir de la base de datos EPEE, Feb. 2021 del EIP-USC. 